\title{
High-resolution satellite-based cloud-coupled estimates of total downwelling surface radiation for hydrologic modelling applications
}

\author{
B. A. Forman and S. A. Margulis \\ Department of Civil and Environmental Engineering, University of California at Los Angeles, Los Angeles, California, \\ 90095, USA
}

Received: 26 February 2009 - Published in Hydrol. Earth Syst. Sci. Discuss.: 3 April 2009

Revised: 22 June 2009 - Accepted: 24 June 2009 - Published: 7 July 2009

\begin{abstract}
A relatively simple satellite-based radiation model yielding high-resolution (in space and time) downwelling longwave and shortwave radiative fluxes at the Earth's surface is presented. The primary aim of the approach is to provide a basis for deriving physically consistent forcing fields for distributed hydrologic models using satellite-based remote sensing data. The physically-based downwelling radiation model utilises satellite inputs from both geostationary and polar-orbiting platforms and requires only satellite-based inputs except that of a climatological lookup table derived from a regional climate model. Comparison against groundbased measurements over a 14-month simulation period in the Southern Great Plains of the United States demonstrates the ability to reproduce radiative fluxes at a spatial resolution of $4 \mathrm{~km}$ and a temporal resolution of $1 \mathrm{~h}$ with good accuracy during all-sky conditions. For hourly fluxes, a mean difference of $-2 \mathrm{~W} \mathrm{~m}^{-2}$ with a root mean square difference of $21 \mathrm{~W} \mathrm{~m}^{-2}$ was found for the longwave fluxes whereas a mean difference of $-7 \mathrm{~W} \mathrm{~m}^{-2}$ with a root mean square difference of $29 \mathrm{~W} \mathrm{~m}^{-2}$ was found for the shortwave fluxes. Additionally, comparison against advanced downwelling longwave and solar insolation products during all-sky conditions showed comparable uncertainty in the longwave estimates and reduced uncertainty in the shortwave estimates. The relatively simple form of the model enables future usage in ensemble-based applications including data assimilation frameworks in order to explicitly account for input uncertainties while providing the potential for conditioning estimates from other readily available products derived from more sophisticated retrieval algorithms.
\end{abstract}

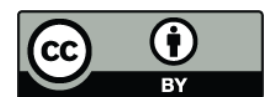

Correspondence to: S. A. Margulis (margulis@seas.ucla.edu)

\section{Introduction}

Characterisation of total radiation reaching the Earth's surface (total downwelling radiation) is necessary for the study of land surface processes and land-atmosphere exchange due to the inherent influence it has on energy availability. Incident surface radiative fluxes have direct connections to applications in hydrology, climate research, agriculture, and renewable energy. Downwelling radiation is the primary external energy forcing at the land surface with the resulting net radiation being a key driver of soil heat flux and photosynthesis processes, as well as sensible and latent heat fluxes (Bras, 1990; Dingman, 2002). Renewable energy markets benefit from accurate characterisation of downwelling broadband shortwave energy for purposes of locating potential sites for photovoltaic arrays (Myers, 2005). Agricultural managers utilise information from the photosynthetically active region of the shortwave spectrum to estimate crop growth and yield (Hunt et al., 1998) as well as information from the longwave spectrum to estimate potential crop damage associated with frost and duration of dew (Diak et al., 2000). Due to the natural variability of downwelling radiation in space and time, however, accurate characterisation of downwelling radiative fields is influenced by evolving cloud conditions that occur over timescales of less than a day and length scales on the order of kilometers (Li et al., 2005).

The primary aim of the approach presented here is to provide a basis for deriving physically consistent radiative forcing fields for distributed hydrologic models using satellitebased remote sensing data. A common argument in distributed model development is the belief that explicit representation of spatially varying fields should lead to significant advances in the skill to simulate and forecast hydrologic response (Beven, 1989). Additionally, nonlinearity of surface

Published by Copernicus Publications on behalf of the European Geosciences Union. 
hydrologic processes often dictates the need for land surface forcing variables at high-resolution in both space and time over large domains (Grayson and Blöschl, 2001). Therefore, in order to properly model the land surface hydrologic response, we are motivated by the desire to create physically consistent radiative flux fields across large regions of space and time. It is our belief that when used in distributed land surface and/or hydrology models, these estimates will lead to improved characterisation of the key modes of variability in land surface states and fluxes. A number of distributed hydrologic models such as the TIN-based Real-time Integrated Basin Simulator (tRIBS, Ivanov et al., 2004) or the Systeme Hydrologique Europeen (MIKE-SHE, Abbott et al., $1986 \mathrm{a}, \mathrm{b})$ as well as distributed applications using land surface models (e.g. Mitchell et al., 2004; Rodell et al., 2004) currently exist that require distributed radiative (and other) forcing fields. Models such as these are the primary intended beneficiaries of our approach.

Two dominant factors result in significant variability in downwelling radiative fluxes across space and time: 1) Earth-Sun geometry, and 2) cloud effects. The motion of the Earth relative to the Sun introduces diurnal and seasonal cycles into downwelling radiative fluxes. The EarthSun geometry effect is easily modelled as a trigonometric series (US Naval Observatory, 2007) that is a function of time and latitude and can be applied at fine spatial and temporal scales. Clouds are equally important in that they are firstorder modulators on downwelling radiation processes (Gautier and Landsfeld, 1997; Pinker and Ewing, 1985; Slingo, 1989), but require more sophisticated methods to account for their radiative influences. Clouds impact both shortwave and longwave flux fields and introduce significant variability in radiation fields as their bulk and microphysical characteristics vary over relatively short spatial and temporal scales (Koren et al., 2008).

Downwelling shortwave and longwave radiation can be accurately measured using in-situ sensors. Unfortunately, a lack of large-scale in-situ networks makes the estimation of downwelling radiation difficult across large regions of space. The availability of satellite-based measurements, however, provides the potential for unprecedented global coverage and horizontal spatial continuity. The main advantage of satellite-based estimation techniques over groundbased techniques is that they can be used to delineate regions where clouds are present with good accuracy. A number of satellite-derived radiation products utilizing complex radiative transfer models have been developed (e.g. Gautier et al., 1980; Pinker and Ewing, 1985; Gupta et al., 1992; Pinker et al., 2003; Meetschen et al., 2004). Many of these models invert satellite-derived brightness temperatures in order to estimate cloud conditions and the subsequent modulation by clouds on the downwelling radiative fluxes. In addition, some of these models require profiles of atmospheric states (e.g. temperature, humidity) that are often based on atmospheric model output. Our approach discussed here employs a relatively simple and computationally efficient formulation that utilises readily available satellite-derived measurements without the need for a radiative transfer model or profiles of atmospheric states.

The model presented here accounts for cloud effects via use of a high-resolution, satellite-based cloud product that provides information on cloud states that can then be used to estimate the modulation of downwelling radiative fluxes. In conjunction with additional satellite-derived atmospheric states and land surface parameters, the cloud information can be used to yield estimates of downwelling radiation that not only account for changes in Earth-Sun geometry, but also explicitly account for cloud effects. The model development was further motivated by the desire to create a relatively simple data-driven model allowing for direct utilisation of a variety of readily available satellite-based inputs. We hypothesise that a simple, bulk physical model derived solely from satellite-based remote sensing observations can be used to generate a prior estimate that captures the coupled space-time patterns, variability, and uncertainty in the key radiative forcings of the land surface. Such a computationally efficient, data-driven bulk model lends itself to use in an ensemble-based data assimilation scheme (e.g. Lee and Margulis, 2007b) where other products, generated at different scales and/or derived from more complex models, can be merged with prior estimates produced by the relatively simple model. In this respect, our model design is not intended to replace more sophisticated models, but rather is expected to ultimately add value to existing products via use of data assimilation schemes.

\section{Satellite-based data}

The model parameterisations presented here are intended to take advantage of satellite-based inputs with varying spatial and temporal characteristics. Between the shortwave and longwave modules, several different satellite-based inputs are utilised: 1) a high-resolution (space and time) cloud product derived from geostationary satellites provides estimates of cloud conditions, 2) a variety of products derived from polar-orbiting satellites provide atmospheric states and land surface parameter information during clear-sky conditions, and 3) multiple atmospheric states from a polarorbiting satellite provide necessary estimates during conditions with cloud cover. Each satellite-based input represents a different atmospheric state (e.g. air temperature) or land surface parameter (e.g. albedo) that impacts downwelling radiative flux fields. All of the products used in this model formulation are readily available and produced in near realtime. Our model approach strikes a compromise between relying minimally on modelled quantities (e.g. does not require high temporal resolution atmospheric profiles necessary for use in radiative transfer schemes), makes the most of available products that are closely related to observable quantities 
Table 1. Spatial and temporal characteristics of model states and parameters derived from satellite-based measurements.

\begin{tabular}{|c|c|c|c|c|c|c|}
\hline \multirow{2}{*}{$\begin{array}{l}\text { Product } \\
\text { Name }\end{array}$} & \multirow{2}{*}{$\begin{array}{l}\text { Required } \\
\text { State/Parameter }\end{array}$} & \multirow[b]{2}{*}{$\begin{array}{l}\text { Orbit } \\
\text { Type }\end{array}$} & \multicolumn{4}{|c|}{ Approximate Scale } \\
\hline & & & $\begin{array}{l}\text { Spectral } \\
\text { Ranore }\end{array}$ & Space & Time & Model \\
\hline AIRS & $\begin{array}{l}\text { Near-surface air } \\
\text { temperature and humidity }\end{array}$ & $P$ & $\begin{array}{l}\text { IR, MW, } \\
\text { NIR, VIS }\end{array}$ & $\sim 50$ & $\sim 1 / 2$ & LW \\
\hline MODIS & $\begin{array}{l}\text { Black-sky albedo } \\
\text { White-sky albedo }\end{array}$ & $P$ & VIS & $\sim 1$ & 16 & SW \\
\hline MODIS & Total precipitable water & $\mathrm{P}$ & IR & $\sim 5$ & $\sim 1 / 2$ & SW \\
\hline MODIS & $\begin{array}{l}\text { Near-surface air } \\
\text { temperature and humidity }\end{array}$ & $P$ & IR, NIR & $\sim 5$ & $\sim 1 / 4$ & LW \\
\hline VISST & $\begin{array}{l}\text { Effective cloud height } \\
\text { Effective cloud temperature } \\
\text { Effective cloud pressure } \\
\text { Cloud base height } \\
\text { Cloud base pressure } \\
\text { Liquid/ice cloud phase } \\
\text { Liquid/ice water path } \\
\text { Effective liquid/ice hydrometeor size }\end{array}$ & G & IR, VIS & $\sim 4$ & $\sim 1 / 48$ & LW, SW \\
\hline
\end{tabular}

$\mathrm{G}=$ Geostationary IR = Infrared LW = Longwave MW = Microwave; NIR = Near Infrared P = Polar; SW = Shortwave; VIS = Visible .

(e.g. utilises measureable cloud states), and maintains physical consistency while keeping the model formulation relatively simple.

One challenge in satellite-based estimation of downwelling radiation is merging a variety of products and choosing an appropriate level of parameterisation within the model. Therefore, prior to presenting the formulations used in the radiation model, it is important to first discuss the available satellite-based inputs used in the model and how data availability motivated much of the parameterisation.

\subsection{Cloud characterisation}

The primary inputs related to bulk cloud radiative properties are estimated via use of the Visible Infrared Solar-infrared Split-window Technique (VISST) product created by the NASA Langley Research Center (Minnis et al., 1995, 2008). Alternative cloud retrieval algorithms (e.g. Kokhanovsky et al., 2005) could have been employed, but VISST was chosen because it is representative of an advanced satellite-derived cloud product. The presence (or absence) of clouds as determined by VISST dictates the inclusion (or exclusion) of cloud properties into the radiative model expressions shown below.

VISST is derived from geostationary satellites with a spatial scale on the order of kilometers and a sub-hourly $(\sim 30 \mathrm{~min})$ temporal scale. Since VISST is at the heart of the radiation model, model output coincides with the spatial and temporal resolution of VISST. The VISST data is generally available in near real-time over the continental US and has been applied to many regions of the globe (Minnis et al., 2008). The pre-processed VISST data used in this study was obtained from an archive at the US Department of Energy's Atmospheric Radiation Measurement (ARM) website (http://www.arm.gov/data/vap_process.php?id=visst).

In the VISST retrieval algorithm, clouds are assumed plane-parallel and to exist as a bulk cloud that fills the entire pixel field of view $(\sim 4 \mathrm{~km} \times \sim 4 \mathrm{~km})$. As a result, problems may arise with capturing scattered sub-kilometer cloud parameters over short ( $\sim$ hourly) time scales (Pinker et al., 1995). In addition, given the columnar arrangement of cloud properties in VISST, layered clouds are not treated explicitly and, instead, are treated as bulk, column-integrated variables. A listing of the cloud states used from the VISST inputs as well as spatial and temporal characteristics of the VISST data is shown in Table 1.

Longwave radiation modulation due to cloud presence requires knowledge of cloud base temperature, phase, and water path. Cloud phase (liquid versus ice) and water path, both of which are provided in VISST, are used to estimate cloud emissivity. Cloud base temperature, however, is not provided in VISST, and as a result must be derived via use of the effective cloud temperature. Using an estimate of the effective cloud elevation and the cloud base elevation that are provided in VISST, the cloud base temperature can be estimated. Solar radiation attenuation by clouds occurs through scattering and absorption. Estimation of these processes requires knowledge of the cloud phase, effective hydrometeor size, and cloud liquid/ice water path. All of these required cloud states are provided in VISST. The details are discussed further in the model methodology section. 


\subsection{Atmospheric characterisation}

In addition to cloud characteristics, additional atmospheric states are required in order to estimate downwelling longwave and shortwave fluxes. The ability to retrieve clear-sky, near-surface measurements of temperature and humidity, which are required in the estimation of downwelling longwave radiation, motivated the use of the Moderate Resolution Imaging Spectroradiometer (MODIS) Air Profile product. The MODIS Air Profile product is available twice daily from both the Terra (MOD07) and Aqua (MYD07) platforms. Each product provides estimates of temperature and humidity at 12 fixed pressure levels. Processing these inputs involves reading measurements from the highest available fixed pressure level (i.e., those closest to the surface). All MODIS-derived inputs were obtained from the NASA MODIS Atmosphere website found at http://ladsweb. nascom.nasa.gov/data/search.html.

A limiting behaviour of MODIS measurements, however, is the inability to see through clouds. When clouds are present, the Atmospheric Infrared Sounder (AIRS) product derived from instrumentation aboard the Aqua platform is used in its place. The AIRS product is based on measurements collected from both the AIRS sensor as well as the $\mathrm{Hu}$ midity Sounder for Brazil (HSB) microwave sensor. As a result, the wavelengths from which the AIRS product is created are more capable of penetrating clouds, and hence can yield estimates of sub-cloud conditions. However, the AIRS product is coarser spatially ( $\sim 50 \mathrm{~km}$ versus $\sim 1 \mathrm{~km})$ and sparser temporally (twice-daily versus four-times daily) compared to MODIS measurements. Therefore, MODIS measurements, when available, are preferred over available AIRS measurements during clear-sky conditions due to the finer spatial and temporal resolution. All AIRS measurements were obtained from the Goddard Earth Sciences Data and Information Center (http://disc.gsfc.nasa.gov/AIRS/).

Estimation of downwelling shortwave flux requires knowledge of precipitable water content in order to estimate water vapour absorption. In the absence of clouds, the shortwave module uses an estimate of the column-integrated precipitable water path. This quantity is derived from measurements in the infrared spectrum during both daytime and nighttime. The Level-2 information is provided twice daily from both the MODIS Terra (MOD05) and MODIS Aqua (MYD05) products. The spatial and temporal scales of the MODIS and AIRS inputs are provided in Table 1.

\subsection{Land surface characterisation}

Additionally, an estimate of the blue-sky (direct plus diffuse) albedo is required in the shortwave formulation, which is derived as a linear function of black-sky (direct) and whitesky (diffuse) land surface albedos. Black-sky and whitesky albedo estimates are obtained from the MODIS Terra Level-3 product (MOD43) for the broadband spectrum rang- ing from 0.3 to 5.0 micrometers and are available at 16-day intervals. This product is useful for capturing slowly varying trends in surface reflectivity (e.g. vegetation growth and senescence). While not a significant issue for the domain used in this study, the relatively sparse temporal nature of the albedo estimates could result in underestimation of surface reflectivity associated with areas of short-lived snow coverage. In such regions, the daily MODIS snow covered albedo product (Hall et al., 2000) could be used to account for snow effects. Table 1 highlights the spatial and temporal characteristics of the MODIS-derived land surface parameters used in the shortwave flux estimation.

\section{Radiation model formulations}

\subsection{Longwave formulation}

Downwelling longwave radiation is formulated as a simple, physically-based bulk expression that accounts for cloud variability. At a given pixel, the longwave module utilises cloudy (or clear) radiative parameterisations based on the presence (or absence) of a cloud. The impact of clouds on downwelling radiative processes are assumed to behave additively such that the downwelling radiation emanated from the cloud base is attenuated by the effective transmissivity of the sub-cloud layer (Diak et al., 2000). The formulation describing downwelling longwave radiation may be written concisely as:

$$
R_{l w}^{\downarrow}(\boldsymbol{x}, t)=\left\{\begin{array}{lc}
\sigma \varepsilon_{a} T_{a}^{4} & \text { clear-sky } \\
\sigma \varepsilon_{a} T_{a}^{4}+\sigma\left(1-\varepsilon_{a}\right) \varepsilon_{c} T_{c}^{4} & \text { cloudy-sky }
\end{array}\right.
$$

where $R_{l w}^{\downarrow}(\boldsymbol{x}, t)$ is the downwelling broadband longwave flux at the Earth's surface, $\sigma$ is the Stefan-Boltzmann constant, $\varepsilon_{a}=0.74+0.0049 e_{a}$ is the effective atmospheric emissivity where $e_{a}$ is the reference-level $(\sim 2 \mathrm{~m}$ above the surface) vapour pressure in millibars (Idso, 1981), $T_{a}$ is the reference-level air temperature, $1-\varepsilon_{a}$ is the effective transmissivity of the sub-cloud layer, $\varepsilon_{c}=1-\exp \left(-k_{c} W\right)$ is the cloud emissivity (Liou, 1992) where $k_{c}$ is the mass absorption coefficient $\left(k_{c} \approx 0.15\right.$ for liquid-phase and $k_{c} \approx 0.06$ for ice-phase), $W$ is the liquid water path or ice water path for liquid-phase and ice-phase clouds, respectively, and $T_{c}$ is the cloud base temperature. Though not explicitly shown, all of the variables on the right-hand side of Eq. (1) are dependent on space $(\boldsymbol{x})$ and time $(t)$. The form of the bulk model shown above is similar to previously used formulations (Diak et al., 2000; Prata et al., 1996) where here the bulk radiative parameters and atmospheric states are estimated from the satellitebased products described above.

\subsubsection{Estimation of reference-level air and cloud base temperature}

As shown in Eq. (1), the downwelling longwave flux field depends on reference-level air and cloud-base temperatures, 
neither of which is provided directly by the MODIS or VISST products. The MODIS product provides air temperatures at fixed pressure levels and the VISST product provides an effective cloud temperature, which is representative of cloud-top conditions.

To estimate reference-level air temperature, $T_{a}$, from the lowest level (highest pressure) MODIS measurement, we make the simplifying assumption of a specified constant ambient adiabatic lapse rate in the layer between the MODIS level and the surface. The ambient lapse rate is assumed to equal $-6.5 \mathrm{~K} \mathrm{~km}^{-1}$ (Cosgrove et al., 2003). Specific humidity as measured by the satellite is assumed to remain constant between the lowest MODIS level and the reference-level elevation. This process is used on the MODIS product during clear-sky conditions as well as the AIRS products in the subcloud layer during cloudy-sky conditions. Tests on the assumed ambient lapse rate were conducted in order to investigate the sensitivity of downwelling longwave flux estimates to this parameter. A dry adiabatic lapse rate of $-9.8 \mathrm{~K} \mathrm{~km}^{-1}$ (Liou, 1992) was used. The resulting maximum temperature difference between the two different lapse rates was $\sim 6 \mathrm{~K}$. Most areas experienced a temperature difference of 1-2 K. These temperature differences produced differences in the downwelling longwave flux, at the most, of $10-15 \mathrm{~W} \mathrm{~m}^{-2}$. The difference in the mean longwave radiation field was typically around $4-5 \mathrm{~W} \mathrm{~m}^{-2}$, which as will be shown later, is within the uncertainty bounds of the model output.

A similar procedure is performed on the VISST estimates of effective cloud temperature. VISST estimates of effective and cloud base heights enable the estimation of cloud base temperature via an assumed moist adiabatic lapse rate, $\Gamma_{m}$. The process is applied analogously to that discussed above and assumes a moist adiabatic lapse rate of $-6.5 \mathrm{~K} \mathrm{~km}^{-1}$ (Hansen et al., 1981; Stephens, 1994).

\subsubsection{Climatologically-based diurnal interpolation for near-surface atmospheric states}

Due to the temporally sparse nature of both the MODIS and AIRS measurements, an interpolation procedure is necessary in order to approximate the diurnal signal in the referencelevel air temperature and humidity. Simple interpolation methods (e.g. linear or spline) will not capture the underlying diurnal cycle from the (at most) 4 daily MODIS measurements. The approach taken here is similar to that used in the so-called triangle method (Gillies et al., 1997) for estimating surface fluxes from temporally sparse surface temperature measurements. The basic premise is to use a representative diurnal signature (climatology) that is then scaled (or stretched) to fit the actual measurements for that day. The climatological diurnal signature could be obtained from ground-based observations, but to allow for general applicability, was derived from a regional climate model (see Appendix A for details) to maintain independence from groundbased data. An additional delineation was made between clear-sky and cloudy-sky conditions in order to derive different climatological signals based on a threshold amount of cloud cover. In any case it is assumed that a representative diurnal climatological signal, $\psi(\boldsymbol{x}, t)$, can be obtained where $\psi$ could be reference-level temperature or humidity.

When two or more satellite measurements are available for a given day at a given location, the temporal interpolation procedure as a function of space and time may be written as:

$$
\begin{aligned}
\xi(\boldsymbol{x}, t) & =[\langle\varphi(\boldsymbol{x})\rangle+\bar{\psi}(\boldsymbol{x})-\langle\psi(\boldsymbol{x})\rangle] \\
& +\frac{\varphi(\boldsymbol{x})_{\max }-\varphi(\boldsymbol{x})_{\min }}{\psi(\boldsymbol{x})_{\max }-\psi(\boldsymbol{x})_{\min }}(\psi(\boldsymbol{x}, t)-\bar{\psi}(\boldsymbol{x}))
\end{aligned}
$$

where $\xi(\boldsymbol{x}, t)$ is the temporally interpolated reference-level state of interest (i.e., temperature or humidity), $\langle\varphi(\boldsymbol{x})\rangle$ is the temporal-average of the satellite measurements, $\bar{\psi}(\boldsymbol{x})$ is the temporal-average of the diurnal climatological values, $\langle\psi(\boldsymbol{x})\rangle$ is the average of the climatological values coincident in time with the satellite measurements, $\varphi(\boldsymbol{x})_{\max }$ is the maximum of the available satellite measurements for the given day, $\varphi(\boldsymbol{x})_{\min }$ is the minimum of the available satellite measurements for the given day, $\psi(\boldsymbol{x})_{\max }$ is the climatological signal coincident in time with $\varphi(\boldsymbol{x})_{\max }, \psi(\boldsymbol{x})_{\min }$ is the climatological signal coincident in time with $\varphi(\boldsymbol{x})_{\min }$, and $\psi(\boldsymbol{x}, t)$ is the climatological signal. The first term (in brackets) serves to shift the climatological mean to the expected value for that day whereas the second term serves to scale the amplitude of the signal. It is important to note that this procedure is not a strict interpolation routine where the estimates go through all of the measurement points, but rather a procedure to fit the measurements using the scaled climatology signal.

Using the climatological signal for air temperature and humidity, the interpolation procedure extracts the most available information regarding the dynamic range measured by MODIS or AIRS for a given day. However, limitations of the MODIS measurements during cloudy conditions dictate the need for an adaptive approach that adjusts when fewer than two satellite observations are available for use in Eq. (2). When one or fewer measurements are available, the reference-level state of interest is assumed equal to either the clear or cloudy model-derived climatological estimate depending on the cloud conditions for the day. When two or more measurements are available, the complete interpolation equation shown in Eq. (2) is used.

Figure 1a shows a representative example of a MODISderived near-surface air temperature timeseries at a given location with four available satellite measurements on 5 October 2003 in Universal Time Coordinates (UTC) where the climatological mean overestimates the measurements. Figure $1 \mathrm{~b}$ shows a similar case on 10 October 2003 except that the climatological mean underestimates the measurements. Ground-based measurements from the Oklahoma Mesonet (Brock et al., 1995) coincident in space with the MODIS measurements are included as evidence of the feasibility of 

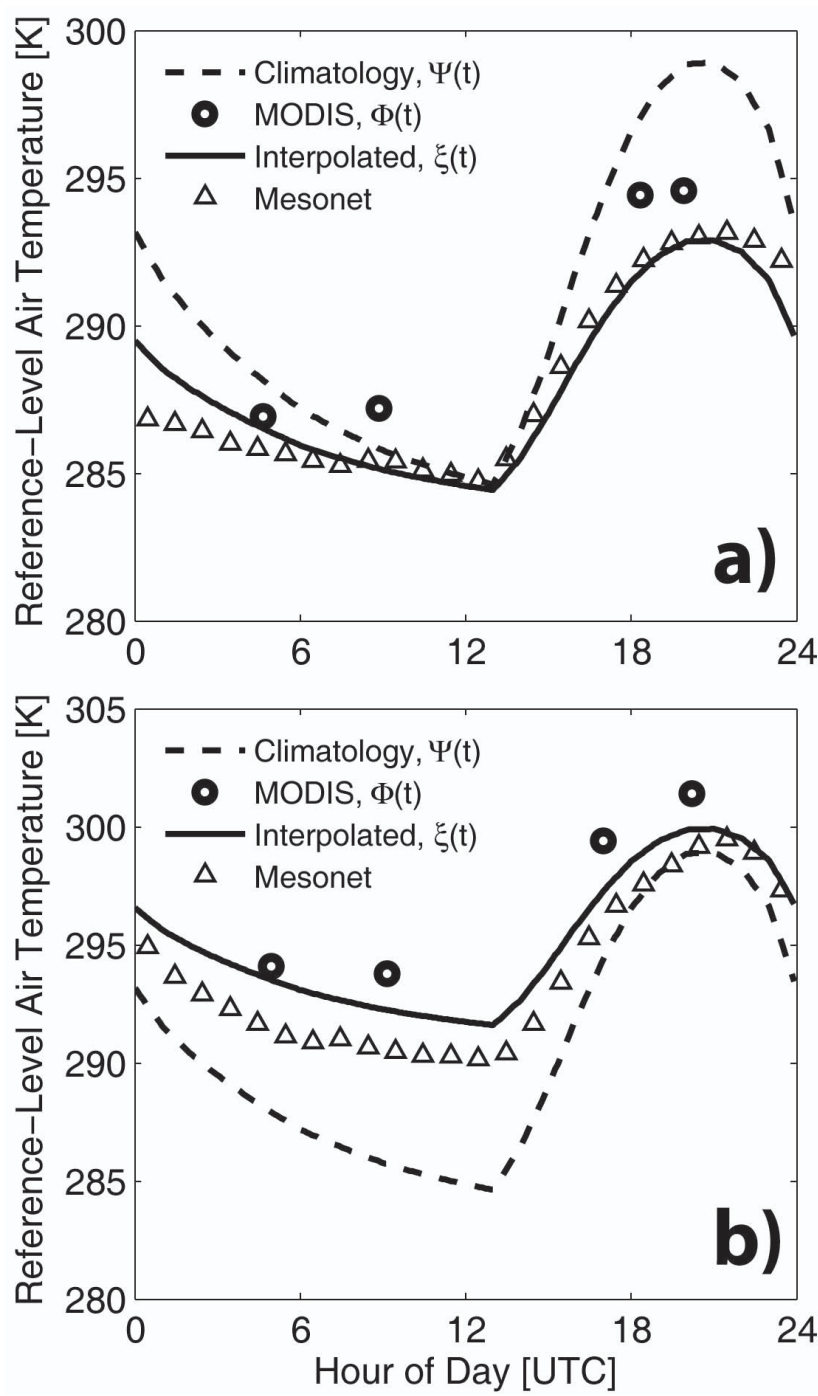

Fig. 1. Example diurnal interpolations of MODIS reference-level air temperature on (a) 5 October 2003 and (b) 10 October 2003 using monthly climatology estimates for use in the longwave module for a location near the middle of the study domain shown in Fig. 2. The available MODIS observations (circles) and hourly-averaged, ground-based Oklahoma Mesonet observations (triangles) are included for reference.

the approach. It is important to note that while the diurnal interpolation procedure will invariably introduce error into the reference-level state estimates, the use of such a fitting procedure (rather than strict interpolation) may alleviate some of the random error in the original satellite-based measurements. Mesonet observations (ground-truth) included in Fig. 1 help illustrate some of the error present in the satellitebased temperature measurements and how application of the fitting procedure can result in reasonable agreement with ground-based observations. Note how the procedure not only adjusts for bias in the satellite measurements but also adjusts the amplitude of the diurnal signal accordingly.

\subsection{Shortwave formulation}

Similar to previous solar insolation models (e.g. Lee and Margulis, 2007a; Gautier et al., 1980), the model presented here employs a single column plane-parallel atmosphere conceptualization at each pixel with clear and cloudy-sky equations depending on the presence or absence of clouds. The two-stream approximation parameterises the effects of Rayleigh and aerosol scattering, diffuse reflected radiation, water vapour and ozone absorption, cloud reflectance and absorption, surface reflection, and multiple reflections between the cloud base and ground surface. The model presented here advances the original Lee and Margulis (2007a) model via inclusion of dynamic blue-sky albedo, diffuse reflected radiation during cloudy-sky conditions, improved water vapour measurements, and a slightly modified parameterisation of ice-phase cloud effects associated with large hydrometeor sizes. Additionally, the model presented here utilises a variety of alternative (e.g. MODIS albedo) and updated (e.g. VISST) satellite-based inputs, which are of higher resolution in space and time and derived from different inference schemes. These modifications resulted in a reduction of more than $50 \%$ of the uncertainty in Lee and Margulis (2007a) when compared against independent, groundbased measurements. Furthermore, the model testing in Lee and Margulis (2007a) was only for a one-month period. The model testing conducted here, as will be discussed further, is for a 14-month period, which includes investigation of seasonality effects.

The formulation describing downwelling shortwave radiation may be written concisely as:

$R_{s w}^{\downarrow}(\boldsymbol{x}, t)= \begin{cases}R_{s w_{o}} \tau_{s w}\left(1+A \alpha_{\mathrm{dif}}\right) & \text { clear-sky } \\ R_{s w_{o}} \tau_{s w}\left(1+A \alpha_{\mathrm{dif}}\right) \frac{\left(1-r_{c}-a_{c}\right)}{\left(1-r_{c} a_{c}\right)} & \text { cloudy-sky }\end{cases}$

where $R_{s w}^{\downarrow}(\boldsymbol{x}, t)$ is the downwelling broadband shortwave flux at the Earth's surface as a function of space $(\boldsymbol{x})$ and time $(t), R_{s w_{o}}$ is the top-of-atmosphere (TOA) incoming flux, $\tau_{s w}$ is the composite shortwave transmissivity representing attenuation by clear-sky absorption and scattering, $A \alpha_{\text {dif }}$ represents the backscattered contribution, $\alpha_{\mathrm{dif}}$ is the contribution of diffuse radiation based on the methods of Lee and Margulis (2007a) which used approximations found in Coulson (1959), $A$ is the blue-sky broadband surface albedo, $r_{c}$ is the cloud reflectance, and $a_{c}$ is the cloud absorptance. Though not explicitly shown, all of the variables on the righthand side of Eq. (3) are dependent on space $(\boldsymbol{x})$ and time $(t)$.

The composite transmissivity is composed of a multiplicative series of physically-based attenuation coefficients and may be expressed as:

$\tau_{s w}=\left(1-\alpha_{a s}\right)\left(1-\alpha_{r s}\right)\left(1-\alpha_{w v}\right)\left(1-\alpha_{\mathrm{O}_{3}, \mathrm{vis}}\right)\left(1-\alpha_{\mathrm{O}_{3}, u v}\right)$

where $\alpha_{a s}$ is the aerosol scattering coefficient, $\alpha_{r s}$ is the Rayleigh scattering coefficient, $\alpha_{w v}$ is the water vapour absorption coefficient, $\alpha_{\mathrm{O}_{3} \text {,vis }}$ is the ozone absorption 
coefficient in the visible spectrum, and $\alpha_{\mathrm{O}_{3}, u v}$ is the ozone absorption coefficient in the ultraviolet spectrum. Each coefficient shown in the right hand side of Eq. (4) varies between 0 and 1 and is a function of space $(\boldsymbol{x})$ and time $(t)$. Equation (4) assumes aerosol absorption is negligible relative to aerosol scattering.

\subsubsection{Shortwave parameterisations}

Descriptions of many of the shortwave cloudy-sky and clearsky parameterisations are omitted for brevity because a discussion is already found in Lee and Margulis (2007a). However, details on the modified parameterisations made in the updated model are provided here. For example, seasonal evolution of blue-sky albedo is included through use of MODIS data. Blue-sky albedo is parameterised as a linear combination of both black-sky albedo, $\bar{A}$, and white-sky albedo, $\hat{A}$. Estimates of $\bar{A}$ and $\hat{A}$ utilise the MODIS-derived land surface albedo product. The blue-sky albedo is then calculated in a manner analogous to Privette et al. (2004) except that the ratio of diffuse skylight relative to total skylight has been replaced by the aerosol scattering attenuation coefficient thereby making aerosol scattering a surrogate for all diffusive processes. This simplification is justified since aerosol scattering tends to dominate diffusive interactions below the Rayleigh atmosphere in the absence of clouds (Coakley et al., 1983). In the presence of optically thick clouds, however, diffuse reflected radiation is insignificant relative to cloud attenuation and scattering processes. Additionally, a modified parameterisation for the scattering and absorption of shortwave radiation by ice-phase clouds was implemented due to problems associated with large hydrometeor sizes. It was found that the original parameterisation of Liou (1992), which was apparently derived for effective hydrometeor sizes up to $100 \mu \mathrm{m}$, produced physically unrealistic (i.e., negative) scattering and absorption coefficients for hydrometeor sizes greater than $132 \mu \mathrm{m}$. Since the change in scattering and absorption by ice-phase clouds is relatively small for hydrometeor sizes greater than $120 \mu \mathrm{m}$, an upper threshold of $132 \mu \mathrm{m}$ was assigned to all ice-phase hydrometeors greater than this threshold value. Comparisons against independent ground-based measurements (results not shown) demonstrate that this modified parameterisation produced physically realistic radiative fluxes in the presence of ice-phase clouds with large hydrometeor sizes without significant loss to radiative flux accuracy.

\section{Model application}

The area selected for the model application in this study is the Southern Great Plains (SGP) of the United States (Fig. 2) and covers a 10-degree by 10-degree spatial domain. SGP is found in the middle of the United States and, for the most part, includes the states of Nebraska, Kansas, Oklahoma, and

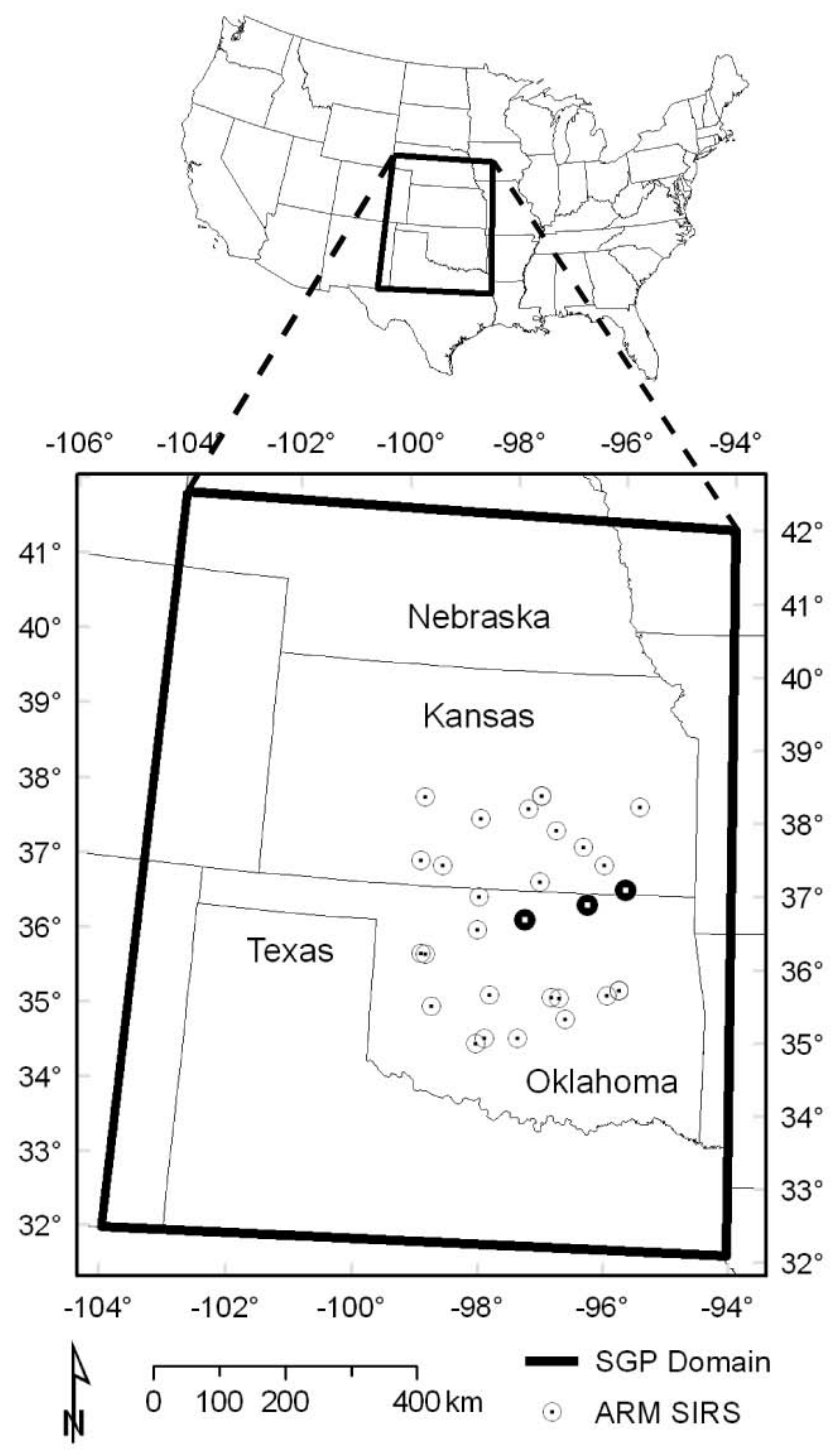

Fig. 2. Southern Great Plains (SGP) domain used in this study as delineated by the thick black line. The dots represent ARM SIRS ground-based measurement locations used for statistical comparisons whereas the filled dots represent station locations used for individual station comparisons in Figs. 5 and 6.

Texas. The SGP are comprised predominantly of grasslands, pasture lands, scrublands, and agricultural croplands. There is a strong west-east precipitation gradient with an eastward increase in annual precipitation (Sharif et al., 2007). The vegetation gradient follows a similar eastward trend of increasing vegetation water content and leaf area index (Pan et al., 2008). The area was chosen because: 1) the relatively homogenous domain allows for the treatment of a satellite pixel field-of-view (order of kilometers) as a homogeneous region, 2) the relatively flat terrain allows for the treatment of radiative fluxes incident upon a horizontal surface, 3 ) the wealth of ground-based measurements in the area allows for 
point-scale comparisons of the satellite-derived model estimates, and 4) SGP serve as a useful proof-of-concept region for model development.

Ground-based stations available for model comparison are the Solar Infrared Radiation Stations (SIRS) operated by the ARM program. The presence of SIRS measurements (shown as dots in Fig. 2) allows for model comparison across a 5degree by 5 -degree domain throughout the diurnal cycle. Differences between the point-scale measurements and the pixel-scale model results are inevitable with this approach. However, these scale differences are minimised in the relatively flat and homogeneous terrain. Comparison against SIRS measurements provides useful guidance as to the quality of the model results and can help identify systematic errors.

Comparison against the satellite-based Shortwave Radiation Budget (SRB) product (Pinker et al., 2003) as well as the model-based downwelling longwave radiation product from the North American Land Data Assimilation System (NLDAS) (Cosgrove et al., 2003) is also performed for reference. The SRB product is based on geostationary measurements and is essentially the NLDAS shortwave product. While satellite-based estimates of shortwave radiation (i.e., SRB) are available, no satellite-based estimates of downwelling longwave radiation in North America on an hourly timescale are readily available for comparison. Rather, the NLDAS longwave product (herein referred to as NLDASLW), which is largely based on Eta Data Assimilation System (EDAS) model output, is used for comparison. Clouds and the Earth's Radiant Energy System (CERES) (Wielicki et al., 1998) and International Satellite Cloud Climatology Project (ISCCP) based longwave flux (Gupta et al., 1992) products are available for comparison; however, the temporal resolutions of the once-daily and three-hourly products, respectively, were considered too coarse for comparison. Subhourly estimates of downwelling shortwave (Geiger et al., 2008) and downwelling longwave (Trigo et al., 2007) radiation are available from the Satellite Application Facility for Land Surface Analysis, but coverage only includes Europe, Africa, the Middle East, and portions of South America. These products would be useful in a global application, but are not applicable in this current study within the SGP domain.

A simulation period of 14-months from 1 August 2003 through 30 September 2004 was selected for this study. These dates were chosen to best yield coincident satellitebased inputs from the VISST, MODIS, and AIRS products. Furthermore, it was desirable to model a minimum of one annual cycle in order to investigate seasonality effects on the modelled radiative fluxes. While some data gaps do exist during this period (e.g. 9-day period starting 1 December 2003 where VISST data was unavailable), these temporal gaps were minimised while simultaneously preserving a continuous investigation period.

\section{Results and discussion}

A variety of analyses were conducted to assess model performance, including qualitative assessment of spatially distributed results as well as quantitative comparison against point-scale measurements. Despite significant differences in scale, comparison against SIRS measurements is deemed the most accurate method for model assessment. The use of SRB and NLDAS-LW products allow for better comparisons of model results across large spatial scales. Since all satellitebased products contain error, SIRS continues to serve as the ground-truth while comparison against both SRB and NLDAS-LW is highlighted to assess the ability of the model to yield spatially explicit estimates of downwelling radiation relative to existing products.

\subsection{Spatially distributed estimates}

Qualitative assessment of model output begins with investigation of instantaneous radiative fluxes distributed across the study domain. Figure 3 shows a representative example of instantaneous model output near local solar noon on $19 \mathrm{Au}-$ gust 2004 and includes plots of some VISST-related state information. For reference, Fig. 3a and b shows VISST inputs of effective cloud temperature and hydrometeor size, respectively. Effective cloud temperature is used to derive cloud base temperature for subsequent use in the longwave module whereas hydrometeor size is needed in the shortwave module. The white (or clear) areas in Fig. 3a and b in the southwestern portion of the domain indicate cloud absence.

The influence of clouds on downwelling longwave radiation is clearly seen in Fig. 3c. The plot in Fig. 3a shows the effective cloud temperature that is used in conjunction with the cloud base elevation and the assumed lapse rate to derive cloud base temperature. Amplified longwave signals are observed when warm clouds with relatively large emissivities are present. The largest longwave fluxes are found in regions with low-lying clouds overlying warm air in the sub-cloud region. The mere presence of clouds, however, does not necessarily equate to amplified longwave radiation. Rather, the cloud base temperature, which is highly dependent on cloud base elevation, coupled with cloud water content, which determines the cloud emissivity, dictates the amount of longwave amplification associated with cloud presence. An example of such behaviour is seen in the northern portions of the domain where clouds are present, but have little impact on the downwelling longwave radiation because they are thin, high-level clouds with relatively little water content.

The influence of clouds on shortwave radiation is clearly seen in Fig. 3d. Note how the thin, high-level clouds in the northern regions of the domain have a smaller impact on solar radiation attenuation compared to the thicker ice-phase clouds found in the middle of the cloud system. These differences in column-integrated cloud structure result in differences in cloud optical thickness that subsequently modulate 

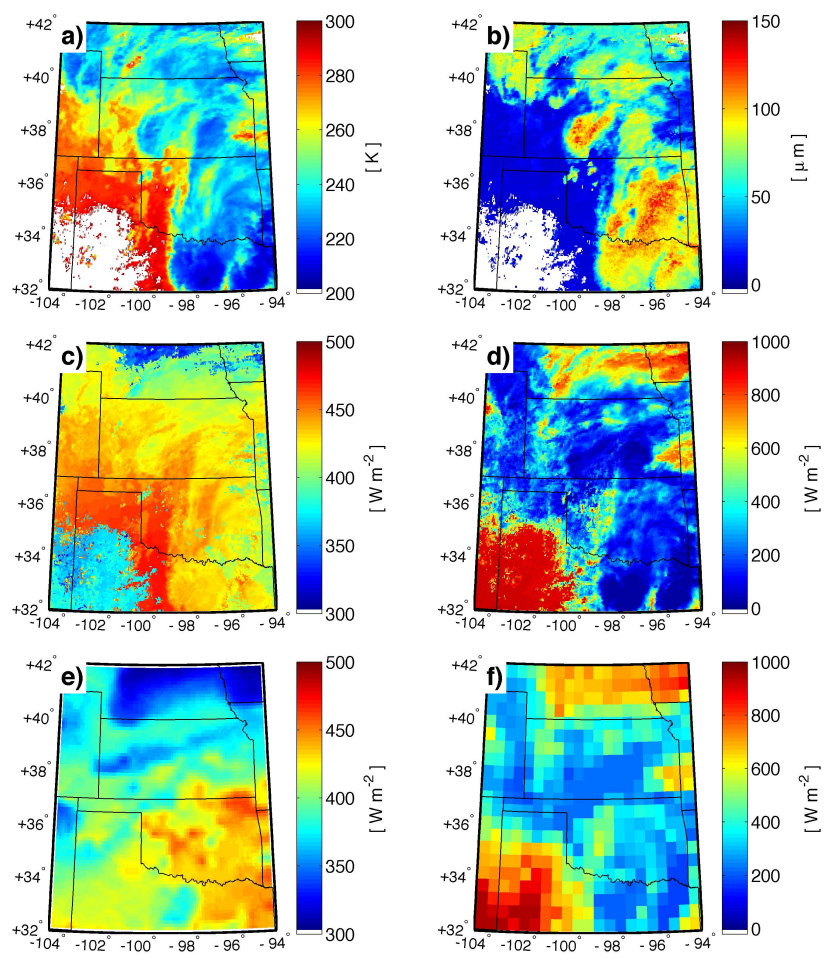

Fig. 3. Instantaneous fields near local solar noon on 19 August 2004 showing (a) VISST-based effective cloud temperature, (b) VISST-based effective cloud hydrometeor size, (c) model estimated downwelling longwave radiation, (d) model estimated downwelling shortwave radiation, (e) NLDAS-derived downwelling longwave radiation, and (f) SRB-derived downwelling shortwave radiation.

the downwelling shortwave radiative flux. In addition, the areas without cloud cover experience the greatest amount of solar insolation since no cloud-related attenuation takes place.

An example of the ability of the model to estimate downwelling radiative flux fields throughout the diurnal cycle as a cloud system evolves is shown in Fig. 4 where longwave radiation is shown on the left and shortwave radiation is shown on the right. Each row of subplots represents a different hour of the day in Universal Time Coordinates (UTC) ranging from about four hours before local solar noon (top), near local solar noon (middle), and about four hours after local solar noon (bottom). As the day progresses, the cloud system migrates and evolves in a complex and dynamic fashion. Due to the explicit inclusion of cloud conditions via use of the VISST product, the radiation model is able to capture these dynamics to yield physically consistent radiative fluxes across space and time. Furthermore, explicit accounting of cloud conditions couples the shortwave and longwave fluxes in an intuitive manner (i.e. regions of thick, low-lying clouds that attenuate shortwave concurrently amplify longwave fluxes).
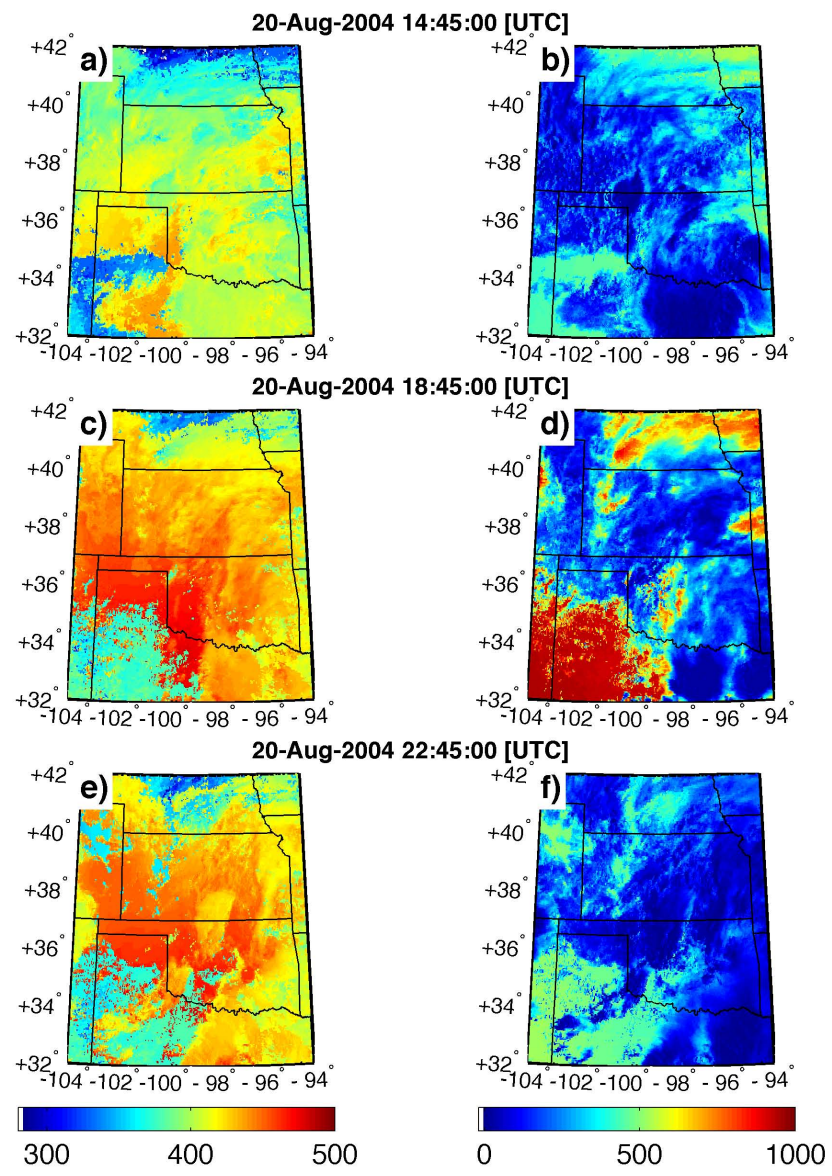

Fig. 4. Example of model output for downwelling longwave (a, $\mathbf{c}$, and $\mathbf{e}$ ) and shortwave (b, d, and f) radiation fields on 19 August 2004 at times 14:45 UTC, 18:45 UTC, and 22:45 UTC, respectively.

\subsection{SRB and NLDAS-LW comparisons}

The plots shown in Fig. 3c and d as well as Fig. 4 appear consistent from a physical standpoint, but are only useful for purposes of qualitative discussion because none of the fields can be completely compared to (or verified by) ground-based observations. However, these plots can at least be qualified via comparison to other spatially distributed radiation products to ensure reasonable spatial distribution of the estimated fluxes. A qualitative comparison of the NLDAS-LW (available at 0.125-degree resolution) and SRB (available at 0.5degree resolution) products near local solar noon is provided in Fig. 3e and f, respectively.

Differences between longwave estimates are pronounced because NLDAS-LW does not always reproduce features associated with dynamic cloud systems. The spatial distribution of the computed longwave flux in Fig. $3 \mathrm{c}$ is consistent with the cloud structure as measured by VISST. The NLDAS-LW product in Fig. 3e, on the other hand, is based on atmospheric model output that does not always accurately predict cloud conditions (Cosgrove et al., 2003). As 


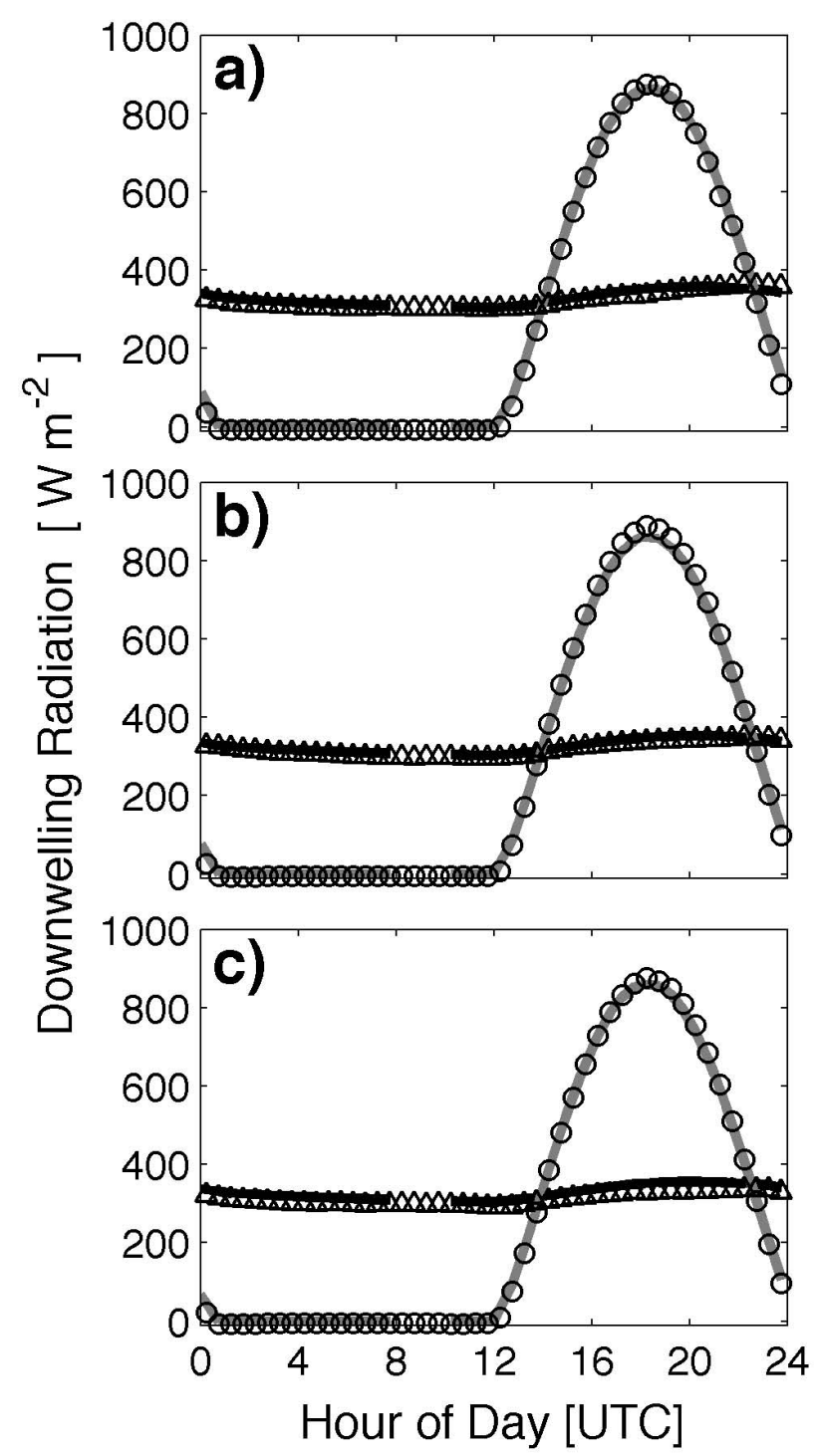

Fig. 5. Instantaneous modelled (black line) and measured (triangles) longwave fluxes as well as instantaneous modelled (grey line) and measured (circles) shortwave fluxes for stations E13, E12, and E10 shown in (a, b, and c), respectively, during clear-sky conditions on 15 September 2003. Example stations E13, E12, and E10 are marked as black dots in Fig. 2 moving from west to east, respectively.

a result, the longwave radiative fluxes are underestimated in the northwestern portion of the domain where significant cloud cover is present. The NLDAS-LW product does an excellent job of producing climatologically consistent estimates of longwave fluxes, but lacks specificity on the dynamics of evolving cloud systems across space and time.

The SRB product (which essentially comprises the NLDAS shortwave product) is shown in Fig. 3f. SRB accounts for the spatial distribution of clouds via use of GOES inputs. Spatial correlation between the computed shortwave fluxes in Fig. 3d and the SRB product shown in Fig. 3f is significant. This is not too surprising considering both estimates are partially derived from the same GOES measurements. The differences in spatial resolution $(\sim 4 \mathrm{~km}$ versus $\sim 50 \mathrm{~km}$ ) demonstrate the ability of the model presented here to capture much of the fine detail while at the same time preserving the large-scale features found in the SRB product. The strong agreement between the shortwave module output and the SRB product, which is derived from a much more sophisticated retrieval algorithm, suggests the model formulation and overall modelling approach presented here is appropriate and can reasonably yield distributed estimates of downwelling shortwave radiation on hourly timescales, making them useful for land surface and/or hydrologic modelling applications.

A final point has to do with the physical consistency of the radiative fields. The model results shown in Fig. $3 \mathrm{c}$ and $\mathrm{d}$ are coupled (physically consistent) since they use the same cloud estimates as inputs. The SRB and NLDAS-LW products (which comprise the total downwelling radiative flux provided in NLDAS) are created independently from one another. With explicit accounting of cloud conditions for only the SRB product, the NLDAS longwave and shortwave fluxes are potentially physically inconsistent, and as such, the accuracy of the combination of the two can be degraded when significant cloud cover is present.

\subsection{Individual station point-scale comparisons}

In addition to the qualitative assessment of the spatially distributed model output, a quantitative assessment comparing model results to all available SIRS ground-based measurements was performed. Model output was first collocated in space and time against SIRS. The SIRS data was carefully reviewed for quality control prior to model comparison, and only station recordings available throughout the entire day were used. Depending on SIRS availability, the number of stations ranged from as few as nine stations to as many as 22 for any given day over the 14-month period. SIRS data is available as one-minute averages, which are used for comparison against instantaneous model output. The estimated SIRS measurement uncertainties are approximately $15 \mathrm{~W} \mathrm{~m}^{-2}$ for shortwave and $6 \mathrm{~W} \mathrm{~m}^{-2}$ for longwave (Dutton et al., 2001).

Figure 5 shows representative instantaneous model results as a function of time in UTC for three example SIRS locations on 15 September 2003, which was a day with little or no cloud coverage in the SIRS measurement domain. The three stations are located near the Kansas-Oklahoma border and are highlighted as the black dots in Fig. 2. During clear-sky conditions, the model compares well against downwelling longwave and shortwave radiation measurements via SIRS. The distance spanned by the stations is large enough that cloud systems could exert substantial differences in radiative fluxes at the three locations; however, in the absence of cloud cover, the radiative fluxes are nearly identical (Fig. 5). The 
shortwave signal is well reproduced in terms of both magnitude and timing. This is not surprising as modelling clear-sky solar insolation is relatively straightforward as compared to when clouds are present. The longwave signal is also well represented with small errors present at station E13 (Fig. 5a) near dusk as well as a small positive bias at the three station locations. The small nighttime gap in the modelled estimates between 07:45 and 10:15 UTC is associated with a systematic gap in the VISST inputs and occurs at all locations on most simulated days.

During cloudy-sky conditions, the model still performs well, but increased variability arises due to the modulation of the radiative flux fields by cloud cover. Figure 6 displays representative results from the same three stations on 29 September 2003 during which a large-scale cloud system moved into the SGP domain. It is clearly seen that the presence of clouds serves to both attenuate shortwave radiation and amplify longwave radiation and that the influence of clouds can be significant over the relatively short spatial scales spanned by the stations. The plots shown in Fig. 6 illustrate the impact of clouds on downwelling radiation (note the jump in longwave radiation coincident with the drop in shortwave radiation shown in Fig. 6c) and the value added by incorporating cloud conditions. The model estimates for this example are able to reasonably capture the spatial and temporal variability in the observed fluxes.

The plots shown in Fig. 6 also illustrate the added variability (and complexity) in modelling radiative fluxes in the presence of clouds. The magnitudes of shortwave radiation are reasonably reproduced at the station locations, but the timing in the variability of the shortwave signal does not exactly reproduce the ground-based measurements. This is a small disparity, but disagreements between satellite inputs and ground-based measurements can often arise due to scale difference, satellite measurement errors, and other sources of uncertainty. Additional errors shown in Fig. 6 include the positive bias seen in the modelled longwave flux estimates due to limited availability of near-surface atmospheric state information from the remote sensing data. In particular, the MODIS sensors cannot penetrate cloud coverage, and as a result, do not provide information at the time of satellite overpass where clouds are present. In some cases of large-scale cloud systems, such as that experienced on 29 September 2003 when one or fewer satellite measurements are available in certain areas due to cloud cover and satellite overpass positioning, the diurnal interpolation algorithm resorts to only using the monthly-derived diurnal climatological lookup table to yield state estimates for the day. The monthly-derived climatological signals are most representative of conditions found near the middle of the month, which in this particular example yielded much warmer temperatures found in midSeptember than found in late-September. Hence, the overestimation of reference-level air temperatures in the climatological lookup table likely explains the positive bias seen in the downwelling longwave radiation for this particular day.

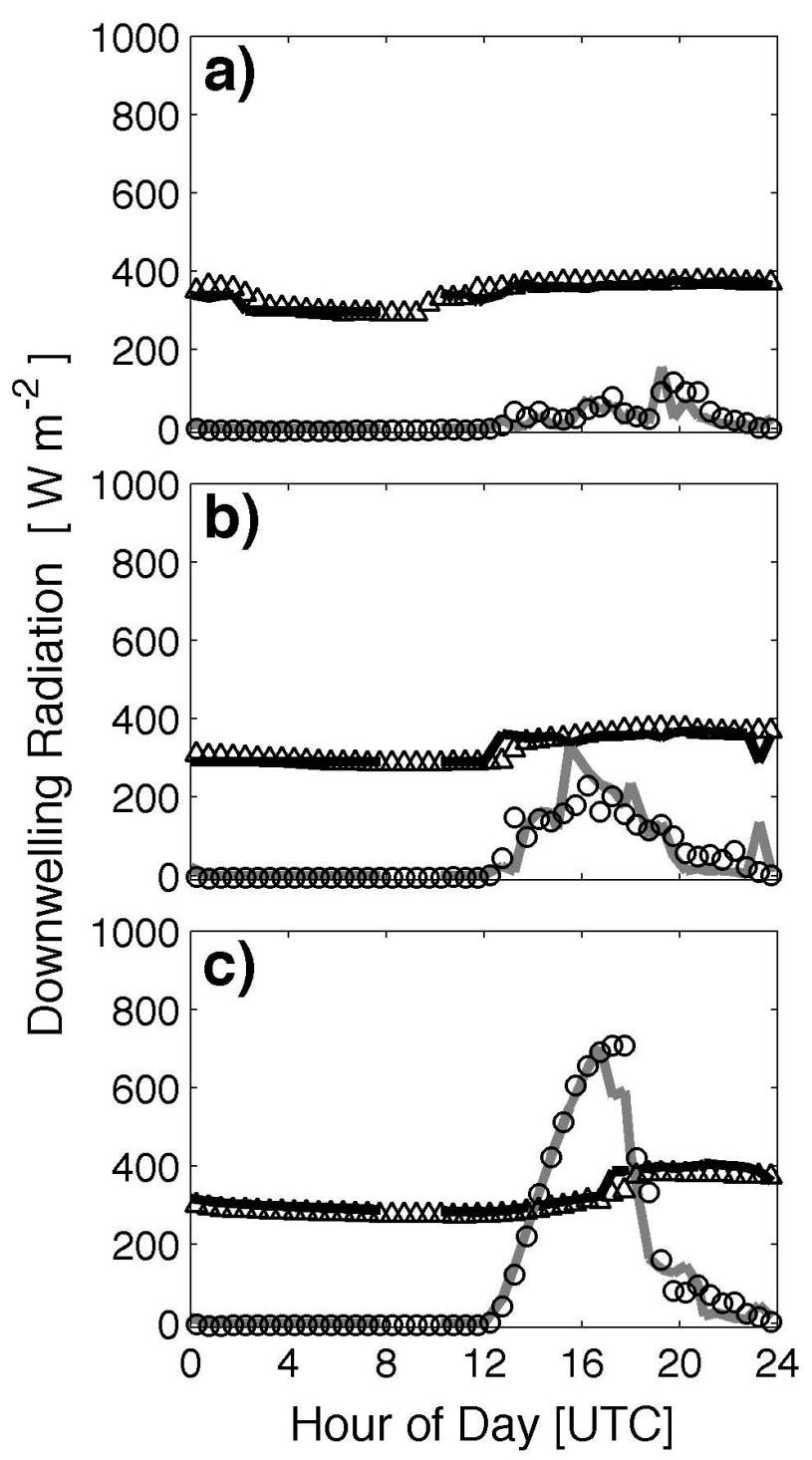

Fig. 6. Same as Fig. 5, but for cloudy-sky conditions on 29 September 2003 .

Future applications could attempt to use a more refined (e.g. weekly or daily) climatological signal.

\subsection{SIRS network-wide comparisons}

The individual station comparisons discussed in the previous section showed the ability of the model to reproduce measured results at a fine-scale in both space and time. Similarly, a network-wide comparison for a given day can help characterize model accuracy across larger spatial domains. To this extent, timeseries from all available SIRS stations (ranging between 9 and 22) for a given day were compared against collocated model output using statistical metrics (i.e., mean difference (MD), root mean square difference (RMSD), and Pearson correlation coefficient $(\rho)$ ) computed for the entire 

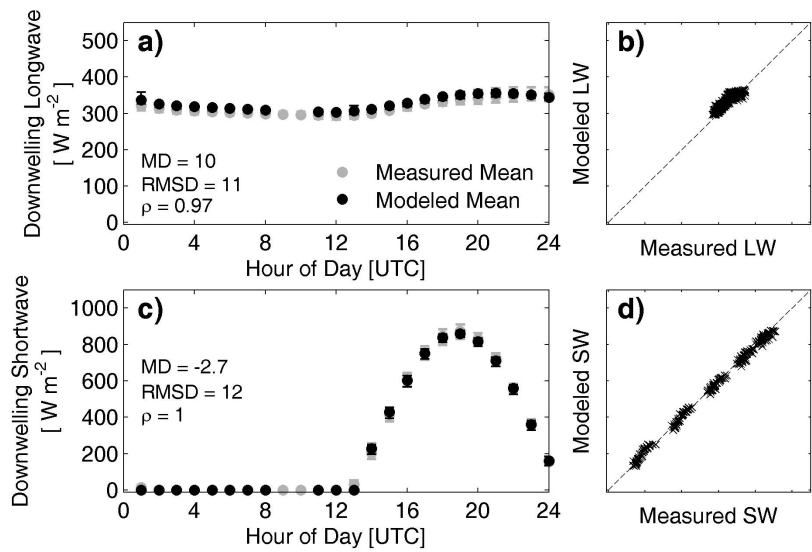

Fig. 7. Hourly-averaged observations and model results during clear-sky conditions showing (a) downwelling longwave radiation and (c) downwelling shortwave radiation on 15 September 2003 in Universal Time Coordinates (UTC). Model results were aggregated to hourly values and 0.125 -degree resolution for longwave and 0.5 degree spatial resolution for shortwave in order to match NLDASLW and SRB, respectively. The circles represent the mean across the 21 station locations whereas the upper-/lower-limits represent the range. Statistics for mean difference (MD), root mean square difference (RMSD), and correlation coefficient $(\rho)$ computed with the mean value of the 21 available stations are included with each subplot. Scatter plots for longwave and shortwave are shown in (b) and (d), respectively.

14-month simulation period. In addition, a comparison of the SRB and NLDAS-LW products to the same SIRS measurements in space and time is made for reference. In order to compare the model with SRB at the same spatial and temporal scale, the shortwave estimates were aggregated in space (from $\sim 4 \mathrm{~km}$ to $\sim 50 \mathrm{~km}$ ) and time (from $\sim$ half-hourly to $\sim$ hourly) in order to match the scales found in the SRB product. Similarly, the longwave estimates were aggregated in space (from $\sim 4 \mathrm{~km}$ to $\sim 12 \mathrm{~km}$ ) and time (from $\sim$ half-hourly to $\sim$ hourly) to match the NLDAS-LW product. Averaging the shortwave results from instantaneous to hourly output included normalisation by the mean solar zenith angle for that hour. In addition, the one-minute SIRS measurements were averaged to one-hour intervals accordingly.

Figure 7 shows a representative clear-sky example of the comparison between model estimates and ground observations for the entire SIRS network on 15 September 2003 when measurements from 21 different stations were available for comparison. As is clearly seen, both the longwave and shortwave modules reproduce the ground-based measurements well and are well correlated across space and time. The lack of spread in each boxplot indicates little variability across the measurement domain on this day. This is because the temperature and humidity (influencing longwave) as well as optical thickness (influencing shortwave) of the overlying atmosphere are relatively consistent across space within the
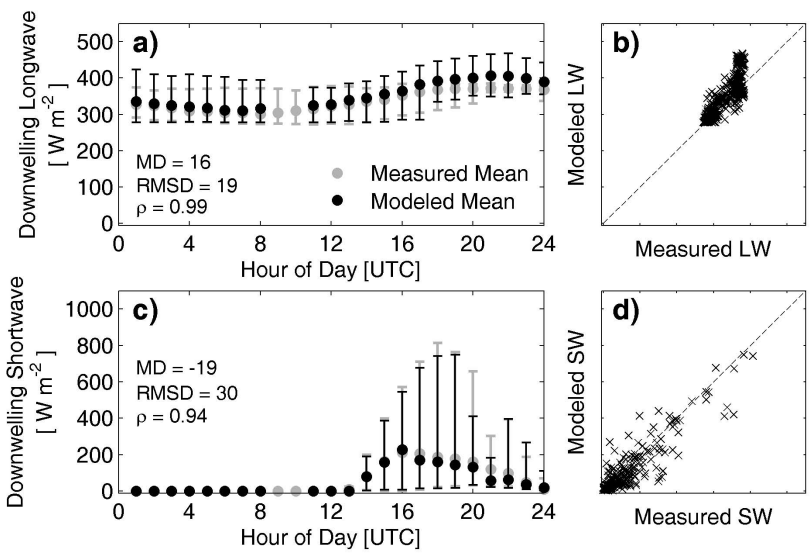

Fig. 8. Same as Fig. 7, but for cloudy-sky conditions on 29 September 2003 measured at 22 stations locations.

measurement domain. Since few clouds are present in the area, little variability in the radiative fluxes occurs. Furthermore, clear-sky conditions offer the opportunity for MODIS sensors to collect near-surface atmospheric state information (i.e., temperature and humidity), which can be then be used during the diurnal interpolation procedure to yield reasonable estimates of air temperature and humidity.

During cloudy-sky conditions, the model continues to perform well, but with more variability associated with the modulation of the radiative fluxes by the overlying clouds. Figure 8 shows an example of model performance during cloudy-sky conditions on 29 September 2003. As expected, the presence of clouds adds a significant amount of variability (and uncertainty) across the measurement domain demonstrated by the spread in the boxplots. The longwave module performance, for example, suffers due to the presence of clouds and is due to two main factors: 1) clouds introduce significant variability in the downwelling longwave flux, which adds complexity to the modelling efforts, and 2) the cloud coverage prevents the MODIS sensor from measuring the near-surface states, which limits the amount of information available for the longwave module to utilise in the diurnal interpolation algorithm. The use of AIRS measurements helps overcome some of the limitations associated with this second issue. However, the limited swath width of AIRS relative to MODIS coupled with the fact that AIRS has a maximum of two SGP overpasses per day to a maximum of four SGP overpasses per day for MODIS severely limits the amount of measurement information available for use in the longwave module. The shortwave module performance is also degraded during the presence of clouds. However, despite the increase in values in the error statistics, the shortwave module continues to perform well relative to other satellite-based models (e.g. Meetschen et al., 2004; Pinker et al., 2003) because it depends mostly on the cloud data and does not depend on the data sources required by the longwave module. 
Analysis of model performance over the entire 14-month simulation period is shown in Table 2 where spatiallyaggregated, hourly-averaged model results are compared against all available SIRS measurements. NLDAS-LW and SRB comparisons are also included for reference. The model compares favorably with the SIRS measurements at an hourly timescale during all-sky conditions. MD values are -2 and $-7 \mathrm{~W} \mathrm{~m}^{-2}$ with RMSD values equal to 21 and $29 \mathrm{~W} \mathrm{~m}^{-2}$ for the longwave and shortwave module, respectively. The modelled shortwave RMSD via comparison to SIRS measurements is less than $73 \%$ of that found in the SRB product. It is worthwhile mentioning that the computed RMSD statistics for SRB are significantly lower than those shown in Pinker et al. (2003) and Lee and Margulis (2007a). Obvious errors in SRB (e.g. zeros/gaps near local solar noon) were excluded prior to computing statistics, as these gaps were often associated with missing GOES inputs. The VISST product (and hence the shortwave module) often experienced these same gaps. In addition, missing values in the SRB product that occurred when the solar zenith angle was near 90 degrees (i.e., near the horizon) were also excluded from the statistical investigation because of a cloud detection limitation in SRB. Finally, computed Pearson correlation coefficients shown in Table 2 provide insight to the temporal correlations between the modeled estimates and the ground-based observations. The shortwave module is almost perfectly correlated with the observations. The longwave module, on the other hand, has a relatively low correlation as compared to the NLDAS-LW estimates. This relatively low correlation is largely due to problems associated with the diurnal interpolation algorithm in the presence of cloud cover as discussed above.

When total downwelling radiation (downwelling LW plus downwelling SW) is investigated, advantages to the implicitly coupled approach in our model are readily apparent. In comparing the modeled downwelling radiation to the combined NLDAS-LW/SRB product, the hourly mean difference is the same between the two estimates (can be seen in Table 2) and hourly RMSD is slightly less, but similar in magnitude (results not shown). The similar overall errors in downwelling radiation result from compensating effects in LW and SW fluxes (i.e. smaller errors in SW with larger errors in LW). However, we argue our model results are more physically consistent in cloudy conditions due to the consistent cloud inputs used. Correlations between daytime-averaged LW and SW fluxes were computed for cloudy days for the SIRS data, our model, and the combined NLDAS-LW/SRB fluxes. During cloudy-sky conditions over the 14-month simulation period the Pearson correlation coefficient between the SW and LW SIRS observations is -0.10 . The negative correlation in the presence of clouds is expected and results from the attenuation of SW fluxes with simultaneous amplification of LW fluxes. When the same analysis is done on our model results, the correlation was found to be -0.07 , which closely agrees with the SIRS value. However, the correla-
Table 2. Hourly-averaged statistics of mean difference (MD), root mean square difference (RMSD), and Pearson correlation coefficient $(\rho)$ using aggregated model results relative to hourly-averaged ARM SIRS ground-based measurements for the period of August 2003 through September 2004. Statistics for NLDAS-LW and SRB are included for reference. A total of 22 stations were used in the comparison.

\begin{tabular}{lcrrrr}
\hline Metric & Units & LW & NLDAS-LW & SW & SRB \\
\hline MD & {$\left[\mathrm{W} \mathrm{m}^{-2}\right]$} & -2 & -5 & -7 & 14 \\
RMSD & {$\left[\mathrm{W} \mathrm{m}^{-2}\right]$} & 21 & 15 & 29 & 40 \\
$\rho$ & {$[-]$} & 0.68 & 0.86 & 0.99 & 0.98 \\
\hline
\end{tabular}

LW = Longwave; SW = Shortwave.

tion between fluxes in cloudy conditions for the combined NLDAS-LW/SRB product was found to be 0.37 . The better agreement between the model correlation and the SIRS correlation (in both magnitude and sign) is additional evidence as to the improved physical consistency resulting from our model formulation.

Table 3 shows further details on model performance as a function of season and cloud cover type (e.g. clear- and cloudy-sky conditions). Clear-sky conditions are arbitrarily defined when less than one-third of the measurements at a given SIRS location during the course of a day coincide with cloud presence. Analogously, cloudy-sky conditions are defined when at least one-third of the measurements at a given location coincide with cloud presence. As expected, both the longwave and shortwave modules perform significantly better during clear-sky conditions compared to cloudy-sky conditions. RMSD values increase during all seasons when cloud cover is present. This increase is moderate in most cases, but it is evident that the impact of clouds adversely affects estimate certainty. The shortwave correlation coefficient remains more or less unaffected by the presence of cloud cover. The longwave correlation coefficient, however, shows significant degradation with cloud cover. This decrease in correlation during cloudy-sky conditions is strongly related to the presence of frontal systems associated with the movement of northern cold fronts moving, in general, from the northwest to the southeast. With the exception of convective storm events, much of the cloud cover in the SGP is associated with the confluence of cold air from the north mixing with warm air from the south. During these situations, the typical diurnal temperature signal used in the MODIS/AIRS interpolation routine is not accurate. For example, often the morning air temperatures will be warmer than afternoon air temperatures on days with cold fronts migrating through the domain. The diurnal interpolation scheme will always yield an estimate with the same basic shape as the original climatological signal with varying degrees of scaling taking place depending on the satellite measurements. Therefore, 
Table 3. Hourly-averaged statistics during clear-, cloudy-, and all-sky conditions using aggregated model results relative to hourly-averaged ARM SIRS ground-based measurements.

\begin{tabular}{|c|c|c|c|c|c|}
\hline Period & Model & Conditions & $\mathrm{MD}\left[\mathrm{W} \mathrm{m}^{-2}\right]$ & $\operatorname{RMSD}\left[\mathrm{W} \mathrm{m}^{-2}\right]$ & $\rho[-]$ \\
\hline \multirow{6}{*}{ Full } & \multirow{3}{*}{ LW } & All-sky & -2 & 21 & 0.68 \\
\hline & & Clear-sky & 4 & 17 & 0.83 \\
\hline & & Cloudy-sky & -4 & 23 & 0.59 \\
\hline & \multirow{3}{*}{ SW } & All-sky & -7 & 29 & 0.99 \\
\hline & & Clear-sky & -2 & 24 & 1.0 \\
\hline & & Cloudy-sky & -9 & 31 & 0.99 \\
\hline \multirow{6}{*}{ JJA } & \multirow{4}{*}{ LW } & All-sky & -8 & 19 & 0.69 \\
\hline & & Clear-sky & -10 & 15 & 0.87 \\
\hline & & Cloudy-sky & -7 & 20 & 0.60 \\
\hline & & All-sky & -1 & 30 & 0.99 \\
\hline & \multirow[t]{2}{*}{ SW } & Clear-sky & 4 & 26 & 1.0 \\
\hline & & Cloudy-sky & -3 & 32 & 0.99 \\
\hline \multirow{6}{*}{ SON } & \multirow{4}{*}{ LW } & All-sky & 4 & 18 & 0.77 \\
\hline & & Clear-sky & 5 & 16 & 0.88 \\
\hline & & Cloudy-sky & 3 & 20 & 0.68 \\
\hline & & All-sky & -4 & 23 & 0.99 \\
\hline & \multirow[t]{2}{*}{ SW } & Clear-sky & 3 & 20 & 1.0 \\
\hline & & Cloudy-sky & -8 & 27 & 0.99 \\
\hline \multirow{6}{*}{ DJF } & \multirow{3}{*}{ LW } & All-sky & 7 & 25 & 0.50 \\
\hline & & Clear-sky & 20 & 23 & 0.74 \\
\hline & & Cloudy-sky & 1 & 26 & 0.39 \\
\hline & \multirow{3}{*}{ SW } & All-sky & -27 & 37 & 0.98 \\
\hline & & Clear-sky & -23 & 30 & 1.0 \\
\hline & & Cloudy-sky & -30 & 41 & 0.97 \\
\hline \multirow{6}{*}{ MAM } & \multirow{3}{*}{ LW } & All-sky & -5 & 23 & 0.69 \\
\hline & & Clear-sky & 6 & 15 & 0.79 \\
\hline & & Cloudy-sky & -12 & 27 & 0.63 \\
\hline & \multirow{3}{*}{ SW } & All-sky & -3 & 26 & 0.99 \\
\hline & & Clear-sky & -2 & 24 & 1.0 \\
\hline & & Cloudy-sky & -3 & 27 & 0.98 \\
\hline
\end{tabular}

LW=Longwave; SW=Shortwave; JJA=June/July/August； SON = September/October/November; DJF = December/January/February; $\mathrm{MAM}=\mathrm{March} /$ April/May.

the interpolated MODIS and/or AIRS timeseries will always contain some degree of a diurnal signal with warmer afternoon temperatures relative to the early morning temperatures. During cold front arrival, this can have a deleterious impact on the longwave estimates and corresponding statistics. This effect is demonstrated in Table 3 during the winter months of December, January, and February (DJF) when the temporal correlation during cloudy-sky conditions is lowest amongst all the simulation periods. Table 3 clearly demonstrates that cloud cover has a dramatic impact on shortwave radiation uncertainty as well as downwelling longwave flux. For longwave fluxes, an accurate estimate of near-surface air temperature, which is complicated by cloudy-sky conditions, is required for accurate estimation of downwelling longwave flux.
Further evidence of the relative importance of cloud cover on radiative flux uncertainty is shown in Fig. 9. Note that both the longwave and shortwave flux uncertainty increases more or less linearly with increasing cloud cover. The variability, and hence uncertainty, of both radiative fluxes is strongly modulated by the presence of clouds with longwave fluxes being impacted to a slightly lesser degree (see Fig. 6 as an example). This is a clear indication that accurate estimation of downwelling radiative fluxes during cloudy-sky conditions is highly dependent on the available cloud information, and that a reduction in uncertainty in downwelling radiative flux fields depends on the accurate characterisation of cloud conditions. 


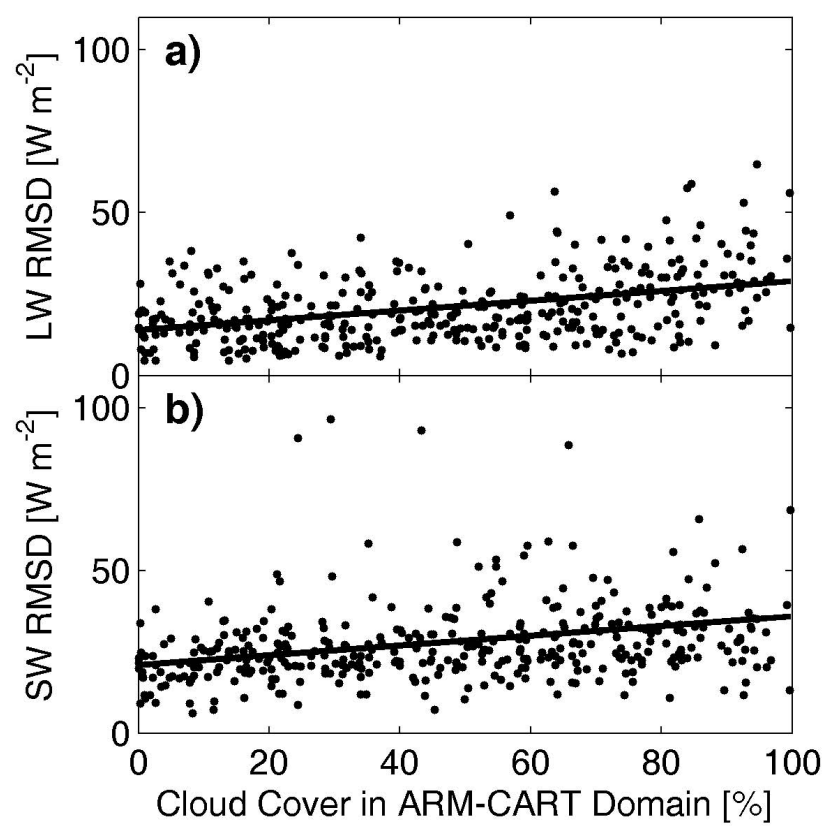

Fig. 9. RMSD for (a) longwave (LW) and (b) shortwave (SW) radiation using temporally- and spatially-aggregated model results as a function of cloud cover. Each data point represents hourly-averaged results over the course of an entire day. The solid dark lines represent simple linear regressions through the data.

\section{Conclusions}

A cloud-coupled model of downwelling longwave and shortwave radiation that solely utilises readily-available satellitebased products is presented and demonstrates considerable skill at reproducing ground-based measurements in the Southern Great Plains (SGP) region of the United States. The physically-based, bulk formulations enable the usage of many different satellite-derived atmospheric states and land surface parameters while maintaining a simple and computationally efficient form. When compared against a readily available, satellite-based estimate of solar insolation (Pinker et al., 2003), the shortwave module compares favorably and yields estimates at a finer scale in both space and time while simultaneously reducing uncertainty. When compared against an advanced downwelling longwave product (Cosgrove et al., 2003), the longwave module produces more physically consistent results (in concert with shortwave fluxes) during cloudy-sky conditions (albeit with higher RMSD), produces comparable amounts of uncertainty during all-sky conditions, and yields estimates at finer scales in space and time. The longwave and shortwave modules produce implicitly coupled (and hence more physically consistent) results via explicit accounting of cloud conditions in both flux fields. For the reference products examined here, only the SRB product explicitly accounts for cloud conditions, which effectively decouples the NLDAS-LW and SRB products allowing for the potential of physical inconsistency in the radiative fields. It is hypothesized that the improved physical consistency could add benefit when the model is applied in a data assimilation scheme. The coupled radiative fields generated by the model presented here could be used as high-resolution (in space and time) forcing fields in distributed hydrologic and land surface modelling applications in an effort to yield a more accurate representation of the land surface hydrologic response.

These initial results are encouraging, and the findings suggest this model formulation is reasonable for application in the SGP. However, it is also important to state the model shortcomings and how future model developments could lead toward improved estimates of downwelling radiative fluxes. For example, the VISST cloud product (and hence the radiation model) does not account for layered clouds. During instances of layered clouds, VISST likely yields cloud property estimates from the upper-most cloud layer (i.e., that most visible by the satellites). This is a potential source of negative bias during cloudy conditions in the longwave module because the low-level clouds are blocked from view by the upper-level clouds, and as a result, the cloud temperature information in VISST is presumably colder than the cloud temperature found in the lower elevation clouds. As a result, the amount of longwave radiation estimated to emanate from the cloud base is presumably lower than that found in reality. Additional shortcomings in the longwave module, as mentioned earlier, include inappropriate temporal interpolation of reference-level atmospheric states during the passing of large-scale cold fronts, as well as an inability to accurately model surface inversions. Future work could investigate use of a different basis function for the interpolation scheme that may be more appropriate for the actual conditions experienced on a particular day (e.g. from a climate model forecast) compared to a climatological basis function. Finally, it has been shown that the longwave formulation used in this model performs poorly for air temperatures below freezing (Satterlund, 1979), which can be quite common during the winter in the northern regions of SGP. The shortwave module demonstrated more skill than the longwave module, but it too could be improved, especially in the treatment of radiative fluxes through optically-thick clouds. Additional testing should also be performed in areas of different climate regimes and/or with more complex terrain.

While the radiation model could be improved, the fact that it performed well in spite of its relatively simple framework is an encouraging first step. This work has demonstrated that a simple bulk data-driven parameterisation is effective so long as the satellite-based inputs used in the model are accurate and can effectively represent the required atmospheric states and land surface parameters. The simple (and computationally efficient) form of this model is by design, and is intended for use in an ensemble-based data assimilation framework. Such an approach, which is presented in a followon study, is an advance over more traditional methods of 

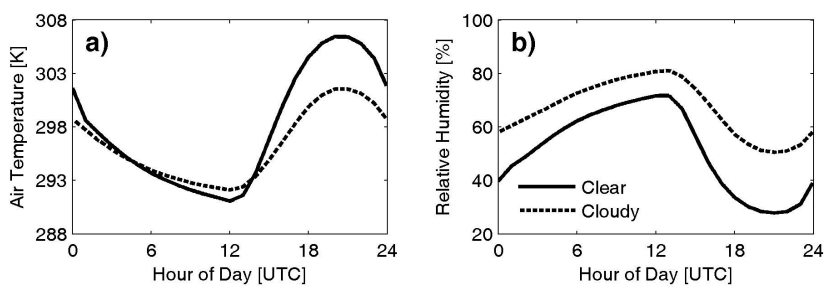

Fig. A1. Example climatological signals near the middle of the study domain during September for clear-sky (solid) and cloudysky (dashed) reference-level temperature and humidity shown in (a) and (b), respectively.

generating an ensemble where a nominal estimate is typically perturbed using additive normal or multiplicative lognormal noise. The traditional approach generally assumes spatially uniform (or correlated) errors across the domain. This type of error formulation does not account for heterogeneity in the error structure, most notably associated with clear- versus cloudy-sky regions, nor does it account for correlated errors associated with regional climatologies. The approach we take in our follow-on paper considers these different sources of error by accounting for cross correlations between errors and their spatial correlations. Shortcomings of the model parameterisations and errors present in the satellite-based inputs can be addressed through this framework via inclusion of parameter and input error and assimilation of estimates of downwelling fluxes derived from more sophisticated retrieval algorithms (e.g. Lee and Margulis, 2007b). This approach could not only improve the modelled estimates via a reduction of modelled uncertainty, but also add value to the existing product used in the assimilation scheme. Radiative forcing fields produced through this methodology could ultimately be used to force distributed land surface models (in offline mode or as part of land data assimilation systems) offering the potential for improved characterisation of the key modes of variability in land surface states and fluxes.

\section{Appendix A}

\section{Derivation of climatological temperature and humidity signals}

The interpolation scheme shown in Eq. (4) requires a climatological diurnal basis function $\psi(\boldsymbol{x}, t)$ that is then shifted and scaled to fit the satellite-observed data. In this application we chose to use a climate model to generate the diurnal basis function for near-surface temperature and humidity. The development of a monthly diurnal climatological database for clear-sky and cloudy-sky conditions was obtained using output from RegCM Version 3 (Giorgi and Mearns, 1999), which is representative of a typical regional climate model. A regional climate model was chosen because most readily available general circulation model
(GCM) output is coarse in space and generally aggregated to at a minimum 3-hourly time steps (e.g. Kanamitsu et al., 2002). The use of a model also makes the radiation model proposed here altogether independent of ground-based observations. While these types of models differ in many of the specific parameterisations used, we argue that a climatology developed from one model would not differ dramatically from that developed using others and that because the climatology is simply a basis function that is then shifted/scaled by the measurements, the impact of these potential differences on the radiation model results will be minimal.

A ten-year continuous simulation from January 1996 through December 2005 over the continental United States was performed for use in deriving diurnal climatological estimates of reference-level air temperature and relative humidity for each month. The RegCM model was run on a $25-\mathrm{km}$ resolution grid utilising aggregated $1-\mathrm{km}$ resolution topography data from the United States Geological Survey and utilised the Biosphere Atmosphere Transfer Scheme (BATS) for land surface processes. The model boundary condition forcings came from the National and Oceanic Atmospheric Administration (NOAA) Optimum Interpolation Sea Surface Temperature (OISST) Version 2 dataset (Reynolds et al., 2002) and the National Centers for Environmental Prediction (NCEP)/National Center for Atmospheric Research (NCAR) Reanalysis Project 2 (NNRP2) meteorology dataset (Kanamitsu et al., 2002).

Model output was extracted over the domain shown in Fig. 2 and subsequently used to derive the diurnal climatological signals for reference-level temperature and humidity distributed across a one-degree by one-degree (latitude/longitude) grid for both clear-sky and cloudy-sky conditions for each month. The determinant between a clear and cloudy day (at a given pixel) was based on the columnintegrated cloud water path. The one-degree spatial resolution was chosen to reasonably capture the latitudinal and elevational effects on the climatological signals across the domain, however, a finer spatial resolution could be used. An example of typical diurnal signals for reference-level temperature and humidity for both clear- and cloudy-sky conditions at a given location during the month of September is shown in Fig. A1.

Acknowledgements. The NASA Earth System Science Fellowship (Contract NNX07AN64H) and NASA grants NNG04GO74G and NNG05GE58G funded this work. We also would like to thank the Minnis Research Group at the NASA Langley Research Center, specifically Kirk Ayers and Mandy Khaiyer, for answers to our questions regarding the VISST cloud product. In addition, we thank the comments of two reviewers that helped clarify and improve this manuscript.

Edited by: W. Wagner 


\section{References}

Abbott, M. B., Bathurst, J. C., Cunge, J. A., O'Connell, P. E., and Rasmussen, J.: An Introduction to the European Hydrological System - Systeme Hydrologique Europeen, "SHE", 2: Structure of a Physically-based, Distributed Modelling System, J. Hydrol., 87, 61-77, 1986.

Beven, K. J.: Changing Ideas in Hydrology - The Case of Physically-based Models, J. Hydrol., 105, 157-172, 1989.

Bras, R. L.: Hydrology: An Introduction to Hydrologic Science, Addison-Wesley, Reading, MA, 643 pp., 1990.

Brock, F. V., Crawford, K. C., Elliott, R. L., Cuperus, G. W., Stadler, S. J., Johnson, H. L., and Eilts, M. D.: The Oklahoma Mesonet: A Technical Overview, J. Atmos. Ocean. Tech., 12, 5-19, 1995.

Coakley Jr., J. A., Cess, R. D., and Yurevich, F. B.: The Effect of Tropospheric Aerosols on the Earth's Radiation Budget: A Parameterization for Climate Models, J. Atmos. Sci., 40, 116$138,1983$.

Cosgrove, B. A., Lohmann, D., Mitchell, K. E., Houser, P. R., Wood, E. F., Schaake, J. C., Robock, A., Marshall, C., Sheffield, J., Duan, Q., Luo, L., Higgins, R. W., Pinker, R. T., and Tarpley, J. D.: Real-time and Retrospective Forcing in the North American Land Data Assimilation System (NLDAS) Project, J. Geophys. Res., 108(D22), 8842, doi:10.1029/2002JD003118, 2003.

Coulson, K. L.: Characteristics of the Radiation Emerging from the Top of a Rayleigh Atmosphere I: Intensity and Polarization, Planet. Space Sci., 1, 265-276, 1959.

Diak, G. R., Bland, W. L., Mecikalski, J. R., and Anderson, M. C.: Satellite-based Estimates of Longwave Radiation for Agricultural Applications, Agr. Forest Meteorol., 103, 349-355, 2000.

Dingman, S. L.: Physical Hydrology, 2nd ed., Prentice Hall, Upper Saddle River, NJ, USA, 646 pp., 2002.

Dutton, E. G., Michalsky, J. J., Stoffel, T., Forgan, B. W., Hickey, J., Nelson, D. W., Alberta, T. L., and Reda, I.: Measurement of Broadband Diffuse Solar Irradiance Using Current Commercial Instrumentation with a Correction for Thermal Offset Errors, J. Atmos. Ocean. Tech., 18, 297-314, 2001.

Gautier, C., Diak, G. R., and Masse, S.: A Simple Physical Model to Estimate Incident Solar Radiation at the Surface from GOES Satellite Data, J. Appl. Meteorol., 19, 1005-1012, 1980.

Gautier, C. and Landsfeld, M.: Surface Solar Radiation Flux and Cloud Radiative Forcing for the Atmospheric Radiation Measurement (ARM) Southern Great Plains (SGP): A Satellite, Surface Observations, and Radiative Transfer Model Study, J. Atmos. Sci., 54, 1289-1307, 1997.

Geiger, B., Meurey, C., Lajas, D., Franchistéguy, L., Carrer, D., and Roujean, J.-L.: Near Real-time Provision of Downwelling Satellite Shortwave Radiation Estimates Derived from Satellite Observations, Meteorol. Appl., 15, 411-420, 2008.

Gillies, R. R., Carlson, T. N., Cui, J., Kustas, W. P., and Humes, K. S.: A Verification of the "Triangle" Method for Obtaining Surface Soil Water Content and Energy Fluxes from Remote Measurements of the Normalized Difference Vegetation Index (NDVI) and Surface Radiant Temperature, Int. J. Remote Sens., 18, 3145-3166, 1997.

Giorgi, F. and Mearns, L. O.: Introduction to Special Section: Regional Climate Modeling Revisited, J. Geophys. Res., 104, 6335-6352, 1999.

Grayson, R. and Blöschl, G.: Spatial Patterns in Catchment Hydrology: Observations and Modelling, Cambridge University Press,
New York, 404 pp., 2001.

Gupta, S. K., Darnell, W. L., and Wilber, A. C.: A Parameterization for Longwave Surface Radiation from Satellite Data: Recent Improvements, J. Appl. Meteorol., 31, 1361-1367, 1992.

Hall, D. K., Riggs, G. A., and Salomonson, V. V.: MODIS/Terra Snow Cover Daily L3 Global $500 \mathrm{~m}$ Grid V004, Boulder, CO, USA: National Snow and Ice Data Center,updated daily, 2000.

Hansen, J. E., Johnson, D., Lacis, A. A., Lebedeff, S., Lee, P., Rind, D., and Russell, G.: Climate Impact of Increasing Atmospheric Carbon Dioxide, Science, 213, 957-266, 1981.

Hunt, L. A., Kuchar, L., and Swanton, C. J.: Estimation of Solar Radiation for Use in Crop Modelling, Agr. Forest Meteorol., 91, 293-300, 1998.

Idso, S. B.: A Set of Equations for Full Spectrum and 8- to 14- $\mu \mathrm{m}$ and 10.2- to 12.5- $\mu \mathrm{m}$ Thermal Radiation from Cloudless Skies, Water Resour. Res., 17, 295-304, 1981.

Ivanov, V. Y., Vivoni, E. R., Bras, R. L., and Entekhabi, D.: Catchment Hydrologic Response with a Fully Distributed Triangulated Network Model, Water Resour. Res., 40, 102-124, 2004.

Kanamitsu, M., Ebisuzaki, W., Woollen, J., Yang, S.-K., Hnilo, J. J., Fiorino, M., and Potter, G. L.: NCEP-DOE AMIP-II Reanalysis (R-2), B. Am. Meteorol. Soc., 83, 1631-1643, 2002.

Kokhanovsky, A. A., Rozanov, V. V., Burrows, J. P., Eichmann, K.-U., Lotz, W., and Vountas, M.: The SCIAMACHY Cloud Products: Algorithms and Examples from ENVISAT, Adv. Space Res., 36, 789-799, 2005.

Koren, I., Oreopoulos, L., Feingold, G., Remer, L. A., and Altaratz, O.: How small is a small cloud?, Atmos. Chem. Phys., 8, 38553864, 2008, http://www.atmos-chem-phys.net/8/3855/2008/.

Lee, S. and Margulis, S. A.: High-resolution Ensemble Surface Insolation Estimates through Assimilation of Coarse-scale Retrievals into a Simple Physical Model, Part I: Physical Model Development and Accuracy Tests, J. Geophys. Res., 112, D08212, doi:10.1029/2006JD007872, 2007a.

Lee, S. and Margulis, S. A.: High-resolution Ensemble Surface Insolation Estimates through Assimilation of Coarse-scale Retrievals into a Simple Physical Model, Part II: Ensemble Implementation and SRB Data Assimilation, J. Geophys. Res., 112, D10219, doi:10.1029/2006JD007873, 2007b.

Li, Z., Cribb, M. C., Chang, F.-L., Trishchenko, A., and Luo, Y.: Natural Variability and Sampling Errors in Solar Radiation Measurements for Model Validation over the Atmospheric Radiation Measurement Southern Great Plains Region, J. Geophys. Res., 110, D15S19, doi:10.1029/2004JD005028, 2005.

Liou, K. N.: Radiation and Cloud Processes in the Atmosphere, Oxford University Press, New York, 487 pp., 1992.

Meetschen, D., van den Hurk, B. J. J. M., Ament, F., and Drusch, M.: Optimized Surface Radiation Fields Derived from Meteosat Imagery and a Regional Atmospheric Model, J. Hydrometeorol., 5, 1091-1101, 2004.

Minnis, P., Kratz, D. P., Coakley Jr., J. A., King, M. D., Garber, D., Heck, P., Mayor, S., Smith Jr., W. L., Young, D. F., and Ardaini, R.: Clouds and the Earth's Radiant Energy System (CERES) Algorithm Theoretical Basis Document, 135-175, 1995.

Minnis, P., Trepte, Q. Z., Sun-Mack, S., Chen, Y., Doelling, D. R., Young, D. F., Spangenberg, D. A., Miller, W. F., Wielicki, B. A., Brown, R. R., Gibson, S. C., and Geier, E. B.: Cloud Detection in Non-polar Regions for CERES Using TRMM VIRS and Terra and Aqua MODIS Data, IEEE T. Geosci. Remote, 46, 3857- 
3884,2008

Mitchell, K. E., Lohmann, D., Houser, P. R., Wood, E. F., Schaake, J. C., Robock, A., Cosgrove, B. A., Sheffield, J., Duan, Q., Luo, L., Higgins, R. W., Pinker, R. T., Tarpley, J. D., Lettenmaier, D. P., Marshall, C. H., Entin, J. K., Pan, M., Shi, W., Koren, V., Meng, J., Ramsay, B. H., and Bailey, A. A.: The Multi-institution North American Land Data Assimilation System (NLDAS): Utilizing Multiple GCIP Products and Partners in a Continental Distributed Hydrological Modeling Systems, J. Geophys. Res., 109, D07S90, doi:10.1029/2003JD003823, 2004.

Myers, D. R.: Solar Radiation Modeling and Measurements for Renewable Energy Applications: Data and Model Quality, Energy, 30, 1517-1531, 2005.

Pan, M., Wood, E. F., Wojcik, R., and McCabe, M. F.: Estimation of Regional Terrestrial Water Cycle Using Multi-sensor Remote Sensing Observations and Data Assimilation, Remote Sens. Environ., 112, 1282-1294, 2008.

Pinker, R. T. and Ewing, J. A.: Modeling Surface Solar Radiation: Model Formulation and Validation, J. Clim. Appl. Meteorol., 24, 389-401, 1985.

Pinker, R. T., Frouin, R., and Li, Z.: A Review of Satellite Methods to Derive Surface Shortwave Irradiance, Remote Sens. Environ., 51, 108-124, 1995.

Pinker, R. T., Tarpley, J. D., Laszlo, I., Mitchell, K. E., Houser, P. R., Wood, E. F., Schaake, J. C., Robock, A., Lohmann, D., Cosgrove, B. A., Sheffield, J., Duan, Q., Luo, L., and Higgins, R. W.: Surface Radiation Budgets in Support of the GEWEX Continental-Scale International Project (GCIP) and the GEWEX Americas Prediction Project (GAPP), including the North American Land Data Assimilation System (NLDAS) Project, J. Geophys. Res., 108(D22), 8844, doi:10.1029/2002JD003301, 2003.

Prata, A. J.: A New Longwave Formula for Estimating Downward Clear-Sky Radiation at the Surface, Q. J. Roy. Meteorol. Soc., 122, 1127-1151, 1996.

Privette, J. L., Mukelabai, M., Zhang, H., and Schaaf, C. B.: Characterization of MODIS Land Albedo (MOD43) Accuracy with Atmospheric Conditions in Africa, Geoscience and Remote Sensing Symposium, Anchorage, AK, 2004.
Reynolds, R. W., Rayner, N. A., Smith, T. M., Stokes, D. C., and Wang, W.: An Improved In Situ and Satellite SST Analysis for Climate, J. Climate, 15, 1609-1625, 2002.

Rodell, M., Houser, P. R., Jambor, U., Gottschalck, J., Mitchell, K. E., Meng, C.-J., Arsenault, K., Cosgrove, B. A., Radakovich, J., Bosilovich, M. G., Entin, J. K., Walker, J. P., Lohmann, D., and Toll, D.: The Global Land Data Assimilation System, B. Am. Meteorol. Soc., 85, 381-394, 2004.

Satterlund, D. R.: An Improved Equation for Estimating Long-wave Radiation from the Atmosphere, Water Resour. Res., 15, 16491650, 1979.

Sharif, H. O., Crow, W. T., Miller, N. L., and Wood, E. F.: Multidecadal High-resolution Hydrologic Modeling of the ArkansasRed River Basin, J. Hydrometeorol., 8, 1111-1127, 2007.

Slingo, A.: A GCM Parameterization for the Shortwave Radiation Properties of Water Clouds, J. Atmos. Sci., 46, 1419-1427, 1989.

Stephens, G. L.: Remote Sensing of the Lower Atmosphere, Oxford University Press, New York, NY, 523 pp., 1994.

Trigo, I. F., Barroso, C., Freitas, S. C., and Viterbo, P.: Assessment of Algorithms for Land Surface Analysis Downwelling Longwave Radiation at the Surface, Proceedings of the 2007 EUMETSAT Meteorological Satellite Conference, Amsterdam, Netherlands, 2007.

US Naval Observatory (Ed.): The Astronomical Almanac, US Naval Observatory, Washington, DC, 2007.

Wielicki, B. A., Barkstrom, B. R., Baum, B. A., Charlock, T. P., Green, R. N., Kratz, D. P., Lee, R. B., Minnis, P., Smith, G. L., Wong, T., Young, D. F., Cess, R. D., Coakley Jr., J. A., Crommelynck, D. A. H., Donner, L., Kandel, R., King, M. D., Miller, A. J., Ramanathan, V., Randall, D. A., Stowe, L. L., and Welch, R. M.: Clouds and the Earth's Radiant Energy System (CERES): Algorithm Overview, IEEE T. Geosci. Remote, 36, 1127-1141, 1998. 